\title{
Acute and Repeated Effects of Synthetic Cannabinoid Agonism and Cannabinoid Receptor 1 Positive Allosteric Modulation
}

Kristen R. Trexler

krtrexler@mix.wvu.edu

Follow this and additional works at: https://researchrepository.wvu.edu/etd

Part of the Pharmacology Commons, and the Toxicology Commons

\section{Recommended Citation}

Trexler, Kristen R., "Acute and Repeated Effects of Synthetic Cannabinoid Agonism and Cannabinoid Receptor 1 Positive Allosteric Modulation" (2019). Graduate Theses, Dissertations, and Problem Reports. 4040.

https://researchrepository.wvu.edu/etd/4040

This Dissertation is protected by copyright and/or related rights. It has been brought to you by the The Research Repository @ WVU with permission from the rights-holder(s). You are free to use this Dissertation in any way that is permitted by the copyright and related rights legislation that applies to your use. For other uses you must obtain permission from the rights-holder(s) directly, unless additional rights are indicated by a Creative Commons license in the record and/ or on the work itself. This Dissertation has been accepted for inclusion in WVU Graduate Theses, Dissertations, and Problem Reports collection by an authorized administrator of The Research Repository @ WVU.

For more information, please contact researchrepository@mail.wvu.edu. 
Acute and Repeated Effects of Synthetic Cannabinoid Agonism and Cannabinoid Receptor 1 Positive Allosteric Modulation

Kristen R. Trexler

Dissertation submitted

To the Eberly College of Arts and Sciences

at West Virginia University

in partial fulfillment of the requirements for the degree of

Doctor of Philosophy in Psychology

Steven G. Kinsey, Ph.D., Chair

Gregory B. Dudley, Ph.D.

David P. Siderovski, Ph.D.

Cole M. Vonder Haar, PhD.

Department of Psychology

Morgantown, West Virginia

2019

Key words: Cannabinoid, cannabis, drug abuse, withdrawal, allosteric modulation, mice Copyright 2019 Kristen R. Trexler 


\begin{abstract}
Acute and Repeated Effects of Synthetic Cannabinoid Agonism and Cannabinoid Receptor 1

Positive Allosteric Modulation
\end{abstract}

Kristen R. Trexler

Recent years have seen a rise in the diversity and use of synthetic cannabinoids. Currently, there is little known about the effects of specific synthetic cannabinoid compounds. As such, little research has been done evaluating the acute and chronic effects of synthetic cannabinoid administration or the development of tolerance and withdrawal. The present study aimed, in part, to evaluate the acute and repeated effect of a third-generation synthetic cannabinoid, AB-FUBINACA. Mice were treated with AB-FUBINACA $(0.1-3 \mathrm{mg} / \mathrm{kg}$, i.p.) or vehicle and were tested repeatedly in the tetrad battery of assays, which included tests of catalepsy, antinociception, hypothermia, and locomotor activity. A second group of mice was injected with AB-FUBINACA ( $3 \mathrm{mg} / \mathrm{kg}$, s.c.) twice daily for 6 days and were tested daily in tetrad. On the $6^{\text {th }}$ day, withdrawal was precipitated using the cannabinoid receptor antagonist rimonabant $(3 \mathrm{mg} / \mathrm{kg})$, and behavior was scored in the somatic signs of withdrawal tests. $\mathrm{AB}$ FUBINACA exhibited classic acute cannabinoid effects in the tetrad but showed a lack of tolerance and cross-tolerance to THC (50 mg/kg, i.p.). Further, precipitated withdrawal from AB-FUBINACA was of a much smaller magnitude than what is typical of other phyto- and synthetic cannabinoids.

Another aspect of cannabinoid research that has been largely overlooked is the use of assays that are able to detect spontaneous (i.e., abstinence-induced) withdrawal. Previous research has demonstrated that spontaneous withdrawal can be detected with certain assays, like the somatic signs of withdrawal and tail suspension tests. To determine whether an anhedonia test would detect signs of spontaneous withdrawal, mice were trained to consume a sweetened condensed milk mixture over 9 days. During the final 6 days of training, mice were injected twice daily with THC (10 or $50 \mathrm{mg} / \mathrm{kg}$, s.c.) or vehicle. On the $9^{\text {th }}$ day, injections were stopped and mice were tested again at $12 \mathrm{~h}$ and $36 \mathrm{~h}$ abstinence. No changes were observed as a result of spontaneous withdrawal from THC.

Despite recent increases in attention to cannabinoid use disorders, there remains a need for pharmacological interventions. ZCZ011 is a $\mathrm{CB}_{1}$ positive allosteric modulator that increases the effect of $\mathrm{CB}_{1}$ agonists bound at the orthosteric site. We hypothesized that ZCZ011 significantly attenuates behavioral signs of cannabinoid withdrawal. Mice were administered $\Delta^{9}$ THC $(10 \mathrm{mg} / \mathrm{kg}$, b.i.d., s.c.) or vehicle for six days, then withdrawal was precipitated using rimonabant $\left(3 \mathrm{mg} / \mathrm{kg}\right.$, i.p.). As previously reported, $\Delta^{9}$-THC withdrawal induced paw tremors and head twitches. Acute ZCZ011 ( $\geq 10 \mathrm{mg} / \mathrm{kg}$, i.p.) significantly attenuated paw tremors and head twitches. ZCZ011 ( $\geq 10 \mathrm{mg} / \mathrm{kg}$, i.p.) was also administered to mice subjected to spontaneous THC withdrawal. ZCZ011 reduced spontaneous THC withdrawal-induced head twitches and paw tremors. An additional group of mice was injected with ZCZ011 $(10 \mathrm{mg} / \mathrm{kg}$, i.p.) or one of its enantiomers, ZCZ011 A or ZCZ011 B prior to precipitated THC withdrawal. Both ZCZ011 $10 \mathrm{mg} / \mathrm{kg}$ or either enantiomer alone attenuated paw tremors and head twitches. 


\section{ACKNOWLEDGEMENTS}

I would like to thank my lab mates, Molly Crowe, Sara Nass, Floyd Steele and Matt Eckard, the many undergraduate assistants who contributed to these projects and Selena Engebretson,

Rebecca Herod, Pam Darling and Vee Lewis for technical assistance. This project was supported by The National Institutes of Health [DA038714] and the National Institute of General Medicinal Sciences T32 [GM081741]. 


\section{TABLE OF CONTENTS}

1 Introduction

1.1 Endocannabinoid system

1.2 Human synthetic cannabinoid use $\quad 6$

1.3 Cannabis Use Disorder 9

$\begin{array}{ll}\text { 1.4 Positive } \mathrm{CB}_{1} \text { Allosteric Modulation } & 10\end{array}$

$\begin{array}{ll}2 \text { Methods } & 11\end{array}$

2.1 Animals 11

$\begin{array}{ll}2.2 \text { Drugs } & 12\end{array}$

2.3 Withdrawal paradigm 12

$\begin{array}{ll}2.4 \text { Statistical analyses } & 16\end{array}$

3 Results $\quad 17$

3.1 Experiment 1.1: Establish rimonabant-precipitated withdrawal: somatic $\begin{array}{ll}\text { signs model } & 17\end{array}$

3.2 Experiment 2.1: Spontaneous withdrawal in marble burying 18

3.3a Experiment 2.2: Spontaneous withdrawal in somatic signs 19

3.3b Experiment 2.2: Spontaneous withdrawal in somatic signs 20

4 Discussion 20

5 Conclusion $\quad 25$

6 References $\quad 27$

$\begin{array}{ll}\text { Figures } & 39\end{array}$

Appendix A: Analysis of covariance (ANCOVA) for experiments 2, 3a, and 3b 47

$\begin{array}{ll}\text { Appendix B: Table of post hoc analyses } & 48\end{array}$ 


\section{Introduction}

\subsection{Endocannabinoid system}

Cannabinoids are molecules that (1) bind to and activate the cannabinoid (CB) receptors, or (2) share structural homology with known CB receptor ligands (Mechoulam \& Parker, 2012). There are two cannabinoid G-protein coupled receptors, i.e., Cannabinoid receptor subtype 1 $\left(\mathrm{CB}_{1}\right)$ and Cannabinoid receptor subtype $2\left(\mathrm{CB}_{2}\right)$, that affect intracellular signaling through the inhibition of adenylate cyclase (Howlett, 1985). $\mathrm{CB}_{1}$ is expressed primarily in the central nervous system, on GABAergic and glutamatergic neurons (Jacob et al., 2009; Steiner \& Wotjak, 2008), whereas $\mathrm{CB}_{2}$ is expressed primarily in the periphery and also commonly expressed on glial cells and in the brainstem (Finn, 2010). $\mathrm{CB}_{1}$ agonism is associated with psychoactive effects, including mild euphoria, relaxation, motor function disruption, and analgesia, typically reported during cannabis use. Conversely, $\mathrm{CB}_{2}$ is implicated in antiinflammatory and immunosuppressive effects that contribute to analgesia, which is a decrease in pain response (Lombard, Nagarkatti, \& Nagarkatti, 2007). Both exogenous (i.e., externally administered) and endogenous (i.e., internally produced) cannabinoids bind to $\mathrm{CB}_{1}$ and $\mathrm{CB}_{2}$ receptors with moderate to high affinity (Lombard et al., 2007; Singh et al., 2012).

Activation of cannabinoid receptors leads to inhibition of adenylyl cyclase and the activation of mitogen-activated protein kinases, which ultimately cause inhibition of responses to stimuli that would normally depolarize the cell, and can decrease neurotransmitter release. (Freund, Katona, \& Piomelli, 2003; Howlett, 2005; Mackie, 2008). Simultaneously, cannabinoid receptor activation closes $\mathrm{N}$ - and P/Q-type calcium $\left(\mathrm{Ca}^{2+}\right)$ ion channels (Flores, Maldonado, \& Berrendero, 2013; Steiner \& Wotjak, 2008), and, due to freed $G \beta / \gamma$ subunits and reduced cAMP, inward rectifying potassium $\left(\mathrm{K}^{+}\right)$channels are also activated (Deadwyler, Hampson, Mu, Whyte, \& Childers, 1995; Mu, Zhuang, Kirby, Hampson, \& Deadwyler, 1999). Together, these effects contribute to hyperpolarization of the presynaptic neuron, which inhibits neurotransmitter release and decreases excitatory post-synaptic potentials in the postsynaptic neuron.

\subsubsection{Phytocannabinoids}

Phytocannabinoids are compounds derived from the Cannabis plant. Over 60 different cannabinoids have been identified in cannabis, including the well-known and most tested $\Delta^{9}$ tetrahydrocanabinol (THC) (Gaoni \& Mechoulam, 1964). In addition to mild euphoria, THC can 
cause cognitive deficits, such as memory loss and altered time perception (Mechoulam \& Parker, 2012; Morgan, Schafer, Freeman, \& Curran, 2010).

\subsubsection{Endocannabinoids}

Endogenously produced cannabinoids (i.e., endocannabinoids) are produced in humans and are evolutionarily well preserved across vertebrates (Fisar, 2009). The two well-established endocannabinoids are 2-arachidonoyl glycerol (2-AG) and $\mathrm{N}$-arachydonoylethanolamine, which is also known as anandamide for the Sanskrit word "ananda" meaning "bliss" (Devane et al., 1992; Mechoulam et al., 1995). Endocannabinoid levels are comparable in most tissues except in the brain, where 2-AG is present in 100-fold higher levels than anandamide (Long et al., 2009). Both endocannabinoids bind to and activate $\mathrm{CB}_{1}$ and $\mathrm{CB}_{2}$ (Lu \& MacKie, 2016; Mechoulam \& Parker, 2012). Unlike neurotransmitters that are produced in the endoplasmic reticulum and stored in vesicles, endocannabinoids are synthesized de novo from lipid precursors, and rapidly released on demand.

Endocannabinoid metabolism is tightly regulated by synthetic and catabolic enzymes. Although there is some controversy, a generally accepted synthetic pathway uses NArachidonoyl-phosphatidylethanolamine specific phospholipase D (PLD) and phospholipase C (PLC) to convert N-Arachidonoyl-phosphatidylethanolamine (NArPE) into anandamide. 2-AG synthesis is more clearly delineated. 2-AG synthesis is more clearly delineated. Diacylglycerols (DAGs) are synthesized by diacylglycerol lipases $\alpha$ and $\beta$ into 2-AG (Di Marzo, 2009; Flores, Maldonado, \& Berrendero, 2013; Howlett, 2005). Anandamide is primarily catabolized by fatty acid amide hydrolase (FAAH) while 2-AG is primarily catabolized by monoacylglycerol lipase (MAGL), and the remaining $\sim 15 \%$ is catabolized by the enzymes ABHD6, ABHD12, and cyclooxygenase (Blankman, Simon, \& Cravatt, 2007; Cravatt et al., 1996; McKinney \& Cravatt, 2005). Chemical inhibition or genetic deletion of either FAAH or MAGL selectively increases anandamide or 2-AG levels, respectively. Enzymatic regulation of endocannabinoids by FAAH and MAGL is extremely efficient, effectively nullifying the exogenous administration of endocannabinoids. Thus, to study effects of the endocannabinoids in vivo, several compounds have been synthesized that act to selectively inhibit the activity of these catabolic enzymes, thereby indirectly increasing brain levels of anandamide or 2-AG.

\subsubsection{Synthetic cannabinoids}


The term "synthetic cannabinoid" technically refers to any lab-produced compound that affects $\mathrm{CB}_{1}$ or $\mathrm{CB}_{2}$ function and includes receptor agonists and antagonists, inhibitors of enzymes mentioned in the previous paragraph, as well as allosteric modulators, which are detailed in section 1.4 (Hess, Schoeder, Pillaiyar, Madea, \& Müller, 2016). Colloquially, "synthetic cannabinoid" refers to a $\mathrm{CB}_{1}$ or $\mathrm{CB}_{2}$ agonist, and for the remainder of this document such compounds will be referred to as synthetic cannabinoids. These compounds were originally synthesized for research purposes, such as receptor/ligand interaction studies, or to selectively agonize one receptor without affecting the other (Banister, Moir, et al., 2015; Banister, Stuart, et al., 2015; Huffman et al., 2005). Once the chemical structures of synthetic cannabinoids were published, clandestine chemists hijacked the compounds and produced so-called "safe" alternatives to cannabis (Jarbe \& Raghav, 2016).

Though some individuals ingest powdered forms of synthetic cannabinoids, the most common route of administration is inhalation of smoked or vaporized plant material treated with one or more of the synthetic cannabinoids (Seely, Lapoint, Moran, \& Fattore, 2012). Solutions of one or more synthetic cannabinoids, in a solvent, are often sprayed onto inert plant material, including blue and pink lotus, skull caps, or rose hips, but may also be applied to plant material containing psychoactive alkaloids (de Havenon, Chin, Thomas, \& Afra, 2011; Dresen et al., 2010; EMCDDA, 2009; Seely et al., 2012). Sold under the broad umbrella term "Spice," these synthetic cannabinoid preparations are labeled "not for human consumption" to avoid regulation by the Food and Drug Administration (Brents, Zimmerman, Saffell, Prather, \& Fantegrossi, 2013), despite their true intended use.

Synthetic cannabinoids are broadly categorized into 7 families, based on chemical structure: cyclohexyl-substituted phenols (e.g., CP 47,497), naphtholindoles (e.g., AM-2201, JWH-018), benzoylindoles (e.g., 6 APB), tetramethylcyclopropylindoles (e.g.,UR-144, XLR 11), adamantoylindoles (e.g., AKB48), indazole carboxamides (e.g.,AB-FUBINACA, AB-PINACA), and quinolinyl esters (e.g., PB22) (Canazza et al., 2016; Ford, Tai, Fantegrossi, \& Prather, 2017; Hess et al., 2016). Though their structures differ, many synthetic cannabinoids act as full agonists at $\mathrm{CB}_{1}$, and in some cases $\mathrm{CB}_{2}$ (Fantegrossi, Moran, Radominska-pandya, \& Prather, 2014; Ford et al., 2017; Hess et al., 2016). Whereas THC is a partial agonist of $\mathrm{CB}_{1}$ and $\mathrm{CB}_{2}$, synthetic cannabinoids often have a relatively lower $\mathrm{K}_{\mathrm{i}}$ value, indicating higher binding affinity, and thus synthetic cannabinoids induce similar cannabimimetic effects to THC, but at relatively 
lower doses (Hess et al., 2016; Wiley et al., 2015). In the "tetrad" battery of cannabinoid behavioral and physiological effects, both first generation (e.g., JWH-018, CP55,940) and later generation (e.g., AB-FUBINACA, AB-CHMINACA) synthetic cannabinoids induce catalepsy, antinociception, and hypothermia in mice (Paronis, Nikas, Shukla, \& Makriyannis, 2012; Wiley et al., 2015). See Table 1 for examples of generational structure differences. Unlike THC, which has dose-dependent sedative effects in rodents, synthetic cannabinoids have inconsistent effects on locomotor activity. For instance, acute high and low dose AB-FUBINACA administration decreased locomotor activity in rats in one study (Kevin et al., 2017), but only high doses induced immobility in two other studies that used mice (Gatch \& Forster, 2015; Schreiber et al., 2018).

Table 1. Structures of representative synthetic cannabinoids by generation.

\begin{tabular}{cccc} 
Generation & Compound & Source \\
\hline First & WIN55-212 & Banister, Stuart, \\
et al., 2015
\end{tabular}


AKB48

5F-PB-22
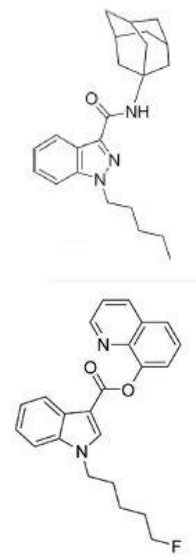

Canazza et al., 2016

While there are many issues associated with human synthetic cannabinoid use, one of the primary concerns is their ever-increasing diversity and the lack of regulation surrounding their creation and distribution. As of 2015, 160 independent synthetic cannabinoid compounds have been identified in samples obtained from shops and over the internet (EMCDDA 2016). Research into synthetic cannabinoids has expanded from exploring primarily pharmacological and behavioral outcomes to include studies of routes of administration, metabolism, and human patterns of synthetic cannabinoid use (Banister, Moir, et al., 2015; Chase et al., 2016; Fantegrossi et al., 2014; Lefever et al., 2017; Su, Seely, Moran, \& Hoffman, 2015; Wiebelhaus et al., 2012). Though many synthetic cannabinoids are assumed to have abuse potential, little work has evaluated the development of tolerance and withdrawal of the newest families of cannabinoids. Further, much of the research done using synthetic cannabinoids rely primarily on physiological and gross behavioral outcomes (Banister, Moir, et al., 2015; Gatch \& Forster, 2015; Kevin et al., 2017), with little attention given to dependence and withdrawal effects.

\subsubsection{AB-FUBINACA}

AB-FUBINACA is a member of the indazole carboxamide family of synthetic cannabinoids that also includes AB-CHMINACA and AB-PINACA, both of which have been linked to deaths in the United States (Trecki, Gerona, \& Schwartz, 2015). AMB-FUBINACA was responsible for a recent series of overdoses in Connecticut. In August of 2018 at least 71 people presented to emergency services with loss of consciousness, vomiting and nausea, and lethargy but displayed no physiological abnormalities (https://www.cbsnews.com/news/newhaven-overdoses-connecticut-new-haven-green-k2-synthetic-marijuana). This absence of AMBFUBINACA induced physiological effects is unusual, as most synthetic cannabinoids induce 
tachycardia, bradycardia, and/or elevated blood pressure in humans (Chinnadurai, Shrestha, \& Ayinla, 2016; Davidson et al., 2017; Mir, Obafemi, Young, \& Kane, 2011). In contrast, ABFUBINACA induces bradycardia in rats (Banister, Moir, et al., 2015). This interspecific difference is likely due to differences in dosing, or perhaps metabolism.

$\mathrm{AB}-\mathrm{FUBINACA}$ is one of the better characterized of the new generation of indazole carboxamide synthetic cannabinoids. AB-FUBINACA induces hypothermia and decreases locomotor activity in both mice (Schreiber et al., 2018) and rats (Banister, Moir, et al., 2015; Kevin et al., 2017) and does not affect nociception in mice (Schreiber et al., 2018) although the lack of antinociception has not been probed in rats. It is somewhat surprising that no data are available on AB-FUBINACA effects on catalepsy, given that catalepsy is a classic cannabinoid effect (Wiley et al., 2015). In a drug discrimination task, AB-FUBINACA fully substitutes for THC, although it also depresses response rate, with incomplete cross-tolerance between the two cannabinoids (Gatch \& Forster, 2015).

Cannabinoids have well-established effects on emotion in people, as well as in experimental animal models. AB-FUBINACA is similar to THC in that it elicits anxiolytic-like effects in low doses in the elevated plus maze, but it diverges from THC by producing anxiogenic-like effects in high doses, in mice (Schreiber et al., 2018). In addition, ABFUBINACA decreases struggling in the forced swim test at a low dose (Schreiber et al., 2018), which is generally indicative of a depressive-like effect, but increases struggling at a high dose, which is generally interpreted as anti-depressive-like or manic effect.

\section{$\underline{1.2 \text { Human synthetic cannabinoid use }}$}

As mentioned in section 1.1.3, synthetic cannabinoids were initially developed for therapeutic purposes (Huffman et al., 2005) although many have been hijacked for recreational use. It is because of this unplanned human use and unpredictable negative effects that synthetic cannabinoids have gained such recent attention. Yet, it is important to keep in mind that, some synthetic cannabinoids have proven effective in attenuating disease states. For instance, JWH133, a selective $\mathrm{CB}_{2}$ agonist, and WIN55,212-2, a nonselective $\mathrm{CB}_{1}$ and $\mathrm{CB}_{2}$ agonist, both inhibit breast tumor growth and metastasis in vitro and in vivo (Olea-Herrero, Vara, MalagarieCazenave, \& Díaz-Laviada, 2009; Qamri et al., 2009). The therapeutic use of synthetic cannabinoids has been severely limited, however, by the presence of side effects in preclinical models, including abuse potential and seizure (Cooper, 2016; de Havenon et al., 2011; Schaefer 
et al., 2013). Thus it is not surprising that, as of October 2018, 1,478 poison control calls regarding synthetic cannabinoid use have been reported ("American Assoication of Poison Control Centers: Synthetic Cannabinoids," 2018). The following sections will focus on the acute and chronic effects of synthetic cannabinoid administration, with an emphasis on the effects in humans, because much of the research and literature on these drugs is effectively playing catchup with clinical reports of what is being used.

\subsubsection{Acute use}

Recreational use of synthetic cannabinoids has increased dramatically in recent years, and with increased use, there has been a concomitant increase in emergency department visits. Few assays currently detect synthetic cannabinoids in blood or urine (Islam et al., 2018; Muehlethaler, Leona, \& Lombardi, 2016; Sobolevsky, Prasolov, \& Rodchenkov, 2010), an issue that is compounded by the ever-changing synthetic cannabinoids used in spice compounds. Thus, it has been difficult to track exactly which synthetic cannabinoid(s) caused a given adverse health episode. Even determining the dose ingested can be difficult, because the plant materials often have "hot spots," as a result of uneven distribution, and high inter- and intra-batch variability in quality and dose (Frinculescu, Lyall, Ramsey, \& Miserez, 2017; Hudson \& Ramsey, 2011; Marshell et al., 2014; van Amsterdam, Brunt, \& van den Brink, 2015). Moreover, of the cases where the compounds involved are known, there is often more than one compound present (Musshoff et al., 2014). Thus, when evaluating the health outcomes of synthetic cannabinoids, they are often grouped together, irrespective of drug family. Regardless of this caveat, synthetic cannabinoids clearly differ from cannabis in their effects.

In humans, acute synthetic cannabinoid use can cause symptoms including: agitation, anxiety, hallucinations, tachycardia, bradycardia, hypotension, diaphoresis, diarrhea, vomiting, myocardia ischemia, and rhabdomyolysis (Benford \& Caplan, 2011; Besli, Ikiz, Yildirim, \& Saltik, 2015; Bhanushali, Jain, Fatima, Leisch, \& Thornley-Brown, 2013; Clark, Georgekutty, \& Berul, 2015; Durand, Delgado, Parra-Pellot, \& Nichols-Vinueza, 2015). Several deaths and serious injuries have been reported following acute synthetic cannabinoid use, including selfmutilation and several suicides, most of which have been attributed to hallucinations (Gay, 2010; Meijer, Russo, \& Adhvaryu, 2014; Patton et al., 2013; Thomas, Kloner, \& Rezkalla, 2014; Trecki et al., 2015). Psychosis induced by synthetic cannabinoid use is so common that some researchers have proposed referring to it as "spiceophrenia" (Papanti et al., 2013). In a study that 
retroactively reviewed emergency room presentations from 16 different locations across Europe, approximately $15 \%$ patients presenting with psychosis reported using synthetic cannabinoid products (Vallersnes et al., 2016). However, these self-report measures are hampered by the inability of users to identify which specific $\operatorname{drug}(\mathrm{s})$ they may have ingested (again, spice products do not list ingredients), as well as polydrug use.

The acute hallucinogenic effects of synthetic cannabinoids may be explained by their indirect effects on dopamine and serotonin, via GABA and glutamate modulation. For example, JWH-018 increases dopamine in the nucleus accumbens in a manner similar to schizophrenia, however, this effect is likely achieved by modulating glutamate and GABA, rather than acting directly on dopamine (El Khoury, Gorgievski, Moutsimilli, Giros, \& Tzavara, 2012; Fantegrossi, Wilson, \& Berquist, 2018). Additionally, synthetic cannabinoids can increase the formation of $5 \mathrm{HT}_{2 \mathrm{~A}}-\mathrm{DA}_{2}$ heterodimers in the prefrontal cortex in rats, which has been implicated as a possible mechanism for the positive symptoms of schizophrenia (Franklin \& Carrasco, 2012). Thus, the presence of psychosis and hallucinations may be explained by synthetic cannabinoid interactions with dopamine and serotonin.

A particularly dangerous, yet poorly understood, side effect of acute synthetic cannabinoid use is seizure. Seizures induced by synthetic cannabinoid use may occur immediately (i.e., within minutes of use) or after a delay of several hours or even days (de Havenon et al., 2011; Schaefer et al., 2013). Although the physiological mechanism(s) are unknown, it is hypothesized that off-target effects, lack of quality control, toxicity (absence of mitigating phytocannabinoids and endocannabinoids), ligand bias, or active metabolites/degradants are likely contributing factors (Chimalakonda et al., 2012; Pertwee, 2009). Further complicating mechanistic studies, the metabolites of many synthetic cannabinoids are active and bind to and activate $\mathrm{CB}$ receptors at similar affinities to the parent compound (Erratico et al., 2015; Fantegrossi et al., 2014). This is in contrast to THC, which has only one psychoactive metabolite, 11-OH-THC (Huestis, 2007; Matsuda, Lolait, Brownstein, Young, \& Bonner, 1990).

\subsubsection{Chronic use}

Little is known about the effects of chronic synthetic cannabinoid administration. One case report indicates that repeated synthetic cannabinoid use may lead to relatively long-term psychosis (Durand et al., 2015). It is plausible that $5 \mathrm{HT}_{2 \mathrm{~A}}$ receptors mediate the psychogenic 
effects of synthetic cannabinoids, because their upregulation in schizophrenia, and following repeated synthetic cannabinoid use, is mediated through $\mathrm{CB}_{1}$ activation (Fantegrossi et al., 2018). A more common effect of chronic drug use is dependence. There is evidence, in both preclinical models and from case reports, that repeated use of synthetic cannabinoids induces tolerance and dependence, as evidenced by withdrawal following cessation of use (Aceto, Scates, \& Martin, 2001; Nacca et al., 2013; Sampson, Bedy, \& Carlisle, 2015; Trexler et al., 2018). The potential for dependence and withdrawal presents a major problem. Currently, cannabis is the most commonly used federally illicit substance for which individuals seek treatment, and there are few effective options for its treatment (Substance Use and Mental Health Services Administration, 2015).

\subsection{Cannabis Use Disorder}

In addition to the acute health risks of cannabis use, such as increased risk of vehicular accidents (Hartman \& Huestis, 2013), chronic use induces varying degrees of dependence. In clinical populations, cannabis dependence, also referred to as Cannabis Use Disorder (CUD), is now routinely tracked by health care professionals. Although only 2-6\% of users are estimated to experience some level of CUD, the overall number of people with some level of CUD is expected to grow as cannabis becomes more widely available (Hasin et al., 2016). CUD is most often characterized by the presence of withdrawal symptoms following cessation of drug use.

Withdrawal symptoms of CUD vary across individuals, but typically include anxiety, depression, sleep disturbances, and can include somatic symptoms, including gastric disturbances and headache (American Psychiatric Association, 2013). The presence of cannabinoid withdrawal symptoms can lead to relapse after cessation (Budney, Vandrey, Hughes, Thostenson, \& Bursac, 2008; Haney et al., 2013). Cognitive behavioral therapies have seen modest short-term success in reducing CUD, with only 19-29\% of individuals maintaining abstinence at a 12-month follow up (Budney, Vandrey, Hughes, Moore, \& Bahrenburg, 2007; Ramesh \& Haney, 2015). Unlike other commonly abused drugs, like opioids or nicotine, there are currently no FDA approved pharmacological therapies to relieve cannabinoid withdrawal symptoms (Allsop, Lintzeris, Copeland, Dunlop, \& McGregor, 2015; Mason, Mustafa, Filbey, Brown, \& Mason, 2016). 
Presently, pharmacological treatments for CUD have focused on its symptoms (e.g., anxiety and depression) or oral administration of THC. For instance, anti-depressant and antianxiety medications that act on noradrenergic, serotonergic and GABAergic targets have been used to treat specific aspects of withdrawal, but are not effective in attenuating withdrawal as a whole (Brezing \& Levin, 2017). Several studies have attempted to treat cannabis withdrawal by administering THC or dronabinol (i.e., synthetically produced $\Delta^{9}$-THC, brand name Marinol), which were unsuccessful at preventing relapse, but did relieve depression associated with withdrawal (Haney et al., 2008, 2004). Combinations of cannabinoid and non-cannabinoid therapies have been effective in attenuating some symptoms of withdrawal, however, they enhance other symptoms, like withdrawal-induced anorexia and sedation (Haney et al., 2008; Levin et al., 2016).

The growing popularity of synthetic cannabinoids, coupled with their unpredictably psychogenic effects, raises concerns about the potential for dependence. Many individuals initiate synthetic cannabinoid use under the age of 25 and have a previous history of using cannabis (Monte et al., 2017; Morean, Kong, Camenga, Cavallo, \& Krishnan-Sarin, 2015). Individuals who initiate cannabis use earlier in life are more likely to develop CUD (Budney et al., 2007). Thus, while the long-term effects of synthetic cannabinoid use are still largely unknown, case reports indicate that the withdrawal syndrome is similar to withdrawal from cannabis, but may be more severe, in one case producing multiple seizures on multiple cessation attempts (Nacca et al., 2013; Sampson et al., 2015). The growing, world-wide use of synthetic cannabinoids highlights the need for effective pharmacological interventions for cannabinoid dependence.

\section{$\underline{1.4}$ Positive $\mathrm{CB}_{1} \underline{\text { allosteric modulation }}$}

An exciting, recently developed research tool that has shown promise in preclinical models is CB receptor allosteric modulation. Positive allosteric modulators (PAMs) bind to the allosteric (i.e., non-orthosteric) sites of receptors, and act to increase the efficacy and/or affinity of orthosteric ligands (Kenakin, 2013). Because they bind to allosteric site(s), rather than the orthosteric site, $\mathrm{CB}_{1}$ PAMs represent an alternative approach for treating cannabinoid-related disorders (Burford, Traynor, \& Alt, 2015; Ross, 2007; Figure 1). For example, the synthetic CB $_{1}$ PAM, GAT211, is antinociceptive in acute mechanical and neuropathic pain models, but does 
not elicit cannabimimetic effects in mice (Slivicki et al., 2017). Our own data indicate that the $\mathrm{CB}_{1}$ PAM ZCZ011 attenuates THC withdrawal, without inducing cannabimimetic side effects, by increasing efficacy or affinity of endocannabinoids (Trexler, Eckard, \& Kinsey, 2019).

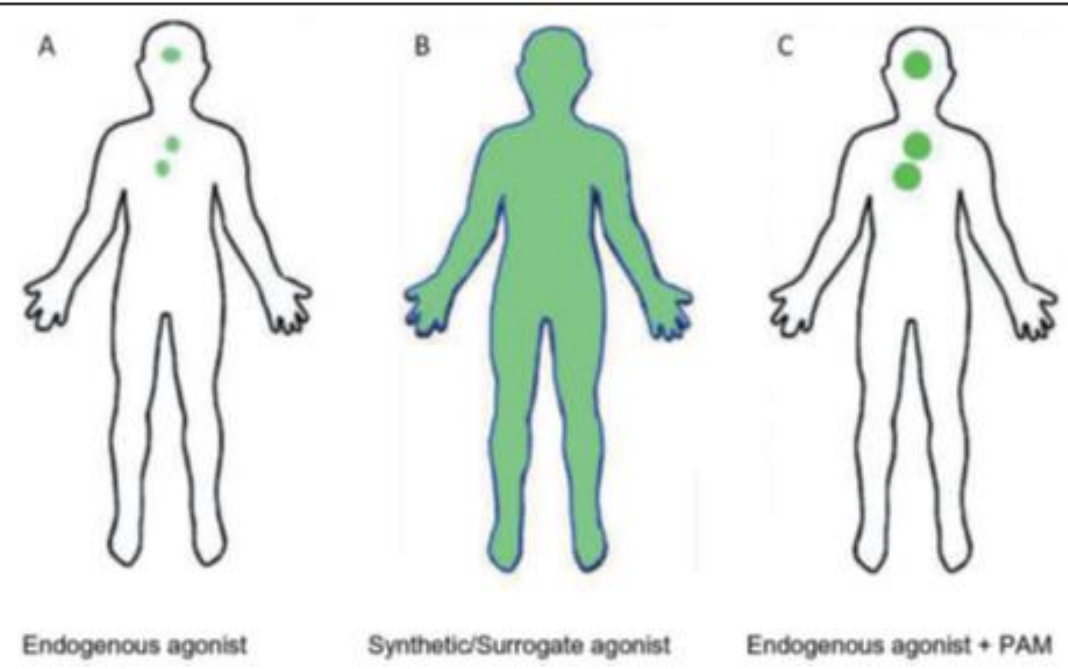

Figure 1. $\mathrm{CB}_{1}$ positive allosteric modulators increase endogenous cannabinoid signaling while maintaining spatial distribution of activity. A. Endocannabinoid activity of a hypothetical physiological process may involve $\mathrm{CB}_{1}$ receptors in the brain and other organs. $\mathrm{B}$. Exogenous administration of a $\mathrm{CB}_{1}$ orthosteric agonist is distributed throughout the body, possibly affecting off-targets. C. $\mathrm{CB}_{1}$ allosteric modulator increases activity of endocannabinoid signaling (From Buford et al., 2015)

The present studies evaluated the behavioral effects of acute and repeated administration of a new generation of synthetic cannabinoid, AB-FUBINACA, and have evaluated both ZCZ011 and its enantiomers as therapeutic targets for THC withdrawal. The goals of these studies were to: 1 . evaluate acute and chronic effects of AB-FUBINACA in the classic cannabinoid tetrad battery; 2. Evaluate the utility of anhedonia as a measure of spontaneous THC withdrawal; and 3. determine the utility of the positive allosteric modulator ZCZ011 and its enantiomers in attenuating THC withdrawal.

\section{Methods}

\subsection{Animals}

Adult male and female C57BL/6J mice (N=589) (The Jackson Laboratory; Bar Harbor, ME) were group housed (4-5 per cage) in Polysulfone plastic cages with food and water available $a d$ libitum. Mice were housed in a single temperature $\left(20-22^{\circ} \mathrm{C}\right)$ and humidity $(50 \pm 5 \%)$ controlled room. Mice were kept on a 12:12 h light/dark cycle and were randomly assigned to each treatment group, such that each cage contained mice from at least two different treatment groups 
(e.g., no cage contained only AB-FUBINACA-treated mice). Experiments that used male and female mice were stratified by sex before random assignment. All experiments were carried out by trained technicians who were blinded to treatment conditions. The Animal Care and Use Committee at West Virginia University approved all experimental protocols prior to the start of any experimental manipulation.

\subsection{Drugs}

The cannabinoid receptor agonists AB-FUBINACA, $\Delta^{9}$-THC, JWH-018, and the selective $\mathrm{CB}_{1}$ receptor antagonist rimonabant (SR141716A) were generously provided by the National Institute on Drug Abuse (NIDA) Drug Supply Program (Bethesda, MD). ZCZ011 was purchased from Axon Medchem (Reston, VA) or provided by a collaborator (Dai Lu, Texas A\&M College of Pharmacy) who also provided the ZCZ011 racemates. All drugs were dissolved in a vehicle composed of 5\% ethanol, 5\% Kolliphor EL (Sigma-Aldrich, St. Louis, MO), and 90\% normal saline (Kinsey \& Cole, 2013). All solutions were warmed to room temperature before administration at a volume of $10 \mu \mathrm{l} / \mathrm{g}$ body mass.

2.2.1 Precipitated withdrawal paradigm: Mice were weighed daily and injected subcutaneously (s.c.) with AB-FUBINACA (1 or $3 \mathrm{mg} / \mathrm{kg}$ ) or vehicle every $12 \mathrm{~h}$ for 6 days, as described previously (Falenski et al., 2010; Schlosburg et al., 2009; Trexler et al., 2018). On the sixth day, all mice received a final injection of AB-FUBINACA or vehicle. After $30 \mathrm{~min}$, mice received an intraperitoneal (i.p.) injection of rimonabant (3 mg/kg) (Lichtman, Fisher, \& Martin, 2001; Trexler et al., 2018) to precipitate withdrawal. Control mice received a vehicle injection on test day.

2.2.2 Spontaneous withdrawal paradigm: Mice were weighed daily and injected subcutaneously (s.c.) with either THC (10 mg/kg) or vehicle every $12 \mathrm{~h}$ for 6 days. Behavioral assessment in the anhedonia assay was conducted $36 \mathrm{~h}$ after the final injection.

\subsection{Behavioral Assessments}

2.3.1 Tetrad: The "Billy Martin tetrad" is a well characterized battery of four assays used to evaluate the effects of cannabinoid agonists (Kinsey \& Cole, 2013; Lichtman et al., 2001; Schlosburg et al., 2010). It consists of: catalepsy, antinociception, core body temperature, and locomotor assessment. Catalepsy was assessed by gently laying the forepaws of individual mice 
over bar $3 \mathrm{~cm}$ above the benchtop. Total latency to move one or both forepaws off the bar was recorded, with a maximum cutoff of 60 s (Long et al., 2009). Antinociception was measured via immersing the distal tip of the tail (i.e., the last $1 \mathrm{~cm}$ ) into a $56^{\circ} \mathrm{C}$ water bath (Falenski et al., 2010). Latency to remove the tail from the water was recorded, with a maximum cutoff of $10 \mathrm{~s}$. Hypothermia was assessed by taking rectal temperature using a micro probe thermocouple thermometer designed for use with mice (BAT-12, Physitemp Instruments Inc., Clifton, NJ, USA). Spontaneous locomotor activity was measured by placing individual mice into an empty test chamber $(30 \mathrm{~cm} \mathrm{~W} \mathrm{x} 40 \mathrm{~cm} \mathrm{~L} \mathrm{x} 16 \mathrm{~cm} \mathrm{H})$ fitted with an overhead video camera, and locomotor activity was scored using ANY-maze video tracking software (Stoetling, Wool Dale, IL) for $5 \mathrm{~min}$. In cases where mice were repeatedly tested a modified tetrad was used which includes only catalepsy, antinociception and hypothermia assessments, as mice habituate to locomotor testing.

2.3.2 Somatic signs testing: Somatic signs of withdrawal were measured as described previously (Trexler et al., 2018). Each mouse was placed into an empty, plastic test chamber $(20 \mathrm{~cm} \mathrm{~W}$ x 20 $\mathrm{cm} \mathrm{L} \mathrm{x} 15 \mathrm{~cm} \mathrm{H}$ ) inside a sound-attenuating chamber outfitted with a fan and white LED lighting. The apparatus had three clear sides and one mirrored side that faced a video camera to allow for observation of behavior when the mouse faced away from the camera.

Mice were habituated to the test apparatus following final AB-FUBINACA or vehicle injection for $30 \mathrm{~min}$ and were then removed and injected with rimonabant or vehicle, as previously reported (Schlosburg et al., 2009). The boxes were cleaned between subjects using a paper towel moistened with distilled water. Each mouse was then be placed back into the test chambers and video recorded for $60 \mathrm{~min}$.

Video files were deidentified and scored by a trained observer. A subset of videos were scored by a second observer to ensure inter-rater reliability $\left(r^{2}=.97\right)$. The dependent variables were incidences of paw tremors and head twitches (i.e., an incidence was scored for 'paw tremor' when the behavior was observed, not for each individual motion). Incidences were considered separate when either (1) another behavior occurred between the incidences, or (2) there was at least $1 \mathrm{~s}$ between incidences (Schlosburg et al., 2009). 
2.3.3 Marble Burying Test: Marble burying was measured as previously described (Broekkamp, Rijk, Joly-gelouin, \& Lloyd, 1986; Trexler et al., 2018), with minor changes. Plastic test chambers (30 cm W x 40 cm L x 16 cm H) filled with Teklad Aspen Sani-Chip (7090A; Envigo, Indianapolis, IN) wood bedding ( $5 \mathrm{~cm}$ deep) were placed inside sound-attenuating chambers outfitted with a fan and LED lighting. A 5 x 5 array of 25 clear glass marbles was laid across the top of the leveled bedding. Each mouse was placed into the chamber and allowed to freely explore for $20 \mathrm{~min}$. At the end of the test, each mouse was quickly and carefully removed and the number of unburied marbles ( $\geq 1 / 3$ of the surface showing) was recorded then subtracted from the 25 total marbles. Marbles were counted by a trained individual. Locomotor activity was simultaneously recorded for the duration of the test by a camera mounted on the top of the test chamber. The video data was analyzed in real time using ANY-maze (Stoetling, Wool Dale, IL) video tracking software.

2.3.4 Tail Suspension Test: The tail suspension test was run as previously described (Kinsey, Bailey, Sheridan, Padgett, \& Avitsur, 2007; Steru, Chermat, Thierry, \& Siman, 1985). Mice were suspended by the tail with adhesive tape from a horizontal bar placed approximately $40 \mathrm{~cm}$ above the benchtop and video recorded for $6 \mathrm{~min}$. The total time the mice actively struggled was hand-scored using ANY-maze (Stoetling, Wool Dale, IL) video tracking software. Active struggling was operationally defined as one or more legs kicking repeatedly within one second, or arching of the spine, but not head movement.

2.3.5 Light/Dark Box: The light/dark box test was conducted as described previously (Crawley \& Goodwin, 1980). The apparatus consisted of two connected Plexiglas chambers, with a small passage hole at floor level. The larger chamber $(30 \mathrm{~cm} \mathrm{~W} \mathrm{x} 40 \mathrm{~cm} \mathrm{~L} \mathrm{x} 30 \mathrm{~cm} \mathrm{H})$ was open and brightly lit by an overhead lamp, and the smaller chamber $(30 \mathrm{~cm} \mathrm{~W}$ x $20 \mathrm{~cm} \mathrm{~L} \mathrm{x} 30 \mathrm{~cm} \mathrm{H}$ ) was covered and constructed using dark red Plexiglas. Each apparatus was placed within a sound attenuating chamber outfitted with a fan and LED lighting. In addition, an infrared LED array (IR3, C\&M Vision Technologies Inc, Houston, TX), along with a video camera (Logitech HD Pro Webcam C920) with the infrared filer removed, were used to visualize the mice. Each mouse was placed in the brightly lit area of the apparatus and allowed to freely explore for $5 \mathrm{~min}$. Locomotor activity was analyzed in real time using ANY-maze software (Stoetling, Wool Dale, 
IL). The dependent variables are total time spent in the dark box, latency to enter the dark box, time immobile, and total distance traveled.

2.3.6 Open field: The open field test was conducted as previously described (Bailey, Kinsey, Padgett, Sheridan, \& Leblebicioglu, 2009). The apparatus consisted of a (40 cm W x $40 \mathrm{~cm} \mathrm{~L} \mathrm{x}$ $30 \mathrm{~cm} \mathrm{H}$ ) box made of black Plexiglas with a white floor. Testing was carried out in individual sound attenuating chambers fitted with LED lighting, a fan, and an overhead video camera. Mice were individually placed into each apparatus and allowed to explore for $10 \mathrm{~min}$. The field was divided evenly into 36 squares which were then divided into two zones: the perimeter, which was the space within $6 \mathrm{~cm}$ of the wall, and the center, which was the remaining $28 \mathrm{x} 28 \mathrm{~cm}$ area not adjacent to the walls (Kinsey et al., 2007). Time spent in the center of the apparatus, distance traveled, and time immobile were quantified in real time using ANY-maze software (Stoetling, Wool Dale, IL).

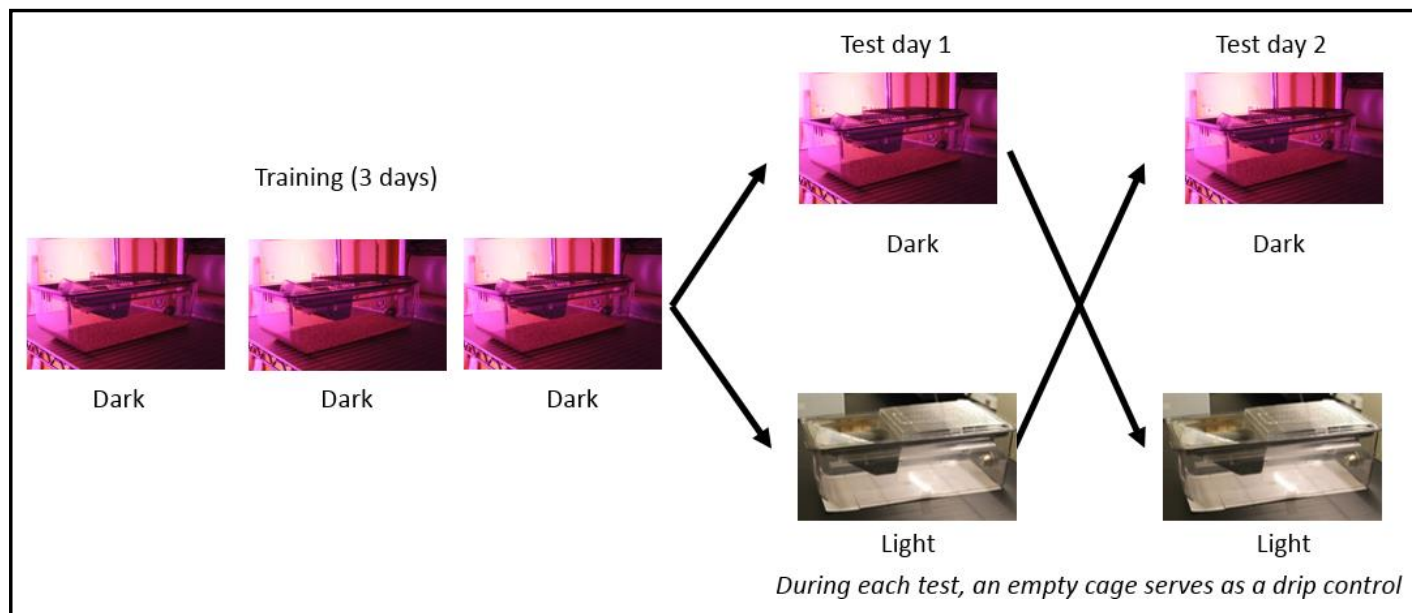

Figure 2. Time line for novelty-induced hypophagia.

2.3.7 Novelty-induced hypophagia: Novelty-induced hypophagia testing was conducted as previously described (Gamble-George et al., 2013), with minor changes. Mice were single housed at least 7 days prior to training. Mice were trained to consume a mixture of 1:3 parts sweetened condensed milk and distilled water under dim light from sipper tubes placed in the home cage. Training took place for 3 days (Figure 2), or until each mouse achieved a threshold of consuming at approximately $1 \mathrm{ml}$ of the sweetened condensed milk mixture, whichever was longer. 
On the first test day, mice were randomly assigned and tested for $30 \mathrm{~min}$ in either the home cage under dim light, or an aversive condition. The dim light condition was the same as the training condition (i.e., 2 lux red light in home cage). The aversive condition consisted of a novel, empty (i.e., no bedding) cage placed on a white floor and brightly lit (1348 lux). On the second test day, mice were tested in the counterbalanced condition. Drug treatments were constant across test days. The following day, each mouse was returned to the training condition and tested again, but without drug. The dependent variable was the volume of sweetened condensed milk consumed. The volume was quantified by subtracting the post-test mass of the bottle from the pre-test mass. A drip control (i.e., a bottle placed in a dummy cage that was not used for testing) was included with each test group to account to for leakage. The data presented represent the total volume consumed, controlled for the drip control for that day.

$$
\left(\text { mass }_{\text {pre }}-\text { mass }_{\text {post }}\right)_{\text {test }}-\left(\text { mass }_{\text {pre }}-\text { mass }_{\text {post }}\right)_{\text {drip control }}
$$

2.3.8 Anhedonia: Anhedonia is a reduced response to a reinforcer, often modeled as decreased drinking of a highly palatable substance. Training was identical to the training phase of noveltyinduced hypophagia. When used to evaluate withdrawal, mice were trained to consume the sweetened condensed milk mixture for 3 days prior to drug administration and continued daily training through the 6-day drug administration phase. On test day, each mouse was habituated to the dim room $35 \mathrm{~h}$ following final drug injection and tested $1 \mathrm{~h}$ later. Volume of sweetened condensed milk consumed was quantified, as in the novelty-induced hypophagia test.

\subsection{Statistical analyses}

For experiment 1, data were analyzed using a repeated measures analysis of variance (ANOVA) with dose as the within subjects variable. For experiment $2 \mathrm{a}$, precipitated withdrawal data were analyzed using a one-way ANOVA. For the spontaneous THC withdrawal experiment, $t$ tests were used to evaluate differences at training day 3 , dosing days and $36 \mathrm{~h}$ abstinence. For experiment 3a, one-way ANOVAs were used, with the exception of novelty-induced hypophagia data, which were analyzed using a mixed design with day as the within subjects variable and drug treatment as the between subjects variable. For experiment $3 \mathrm{~b}$, marble burying and tail suspension data were analyzed using 2x3 ANOVAs. All other studies in experiment $3 \mathrm{~b}$ were analyzed using one-way ANOVAs. Main or interaction effects were followed by Dunnet (e.g., 
for dose-response curves, comparing to vehicle treatment) or Bonferonni post hoc tests, as appropriate. Differences were considered statistically significant if $\mathrm{p}<0.05$.

\section{Results}

The experiments in this study were designed to evaluate both acute and chronic effects of AB-FUBINACA, withdrawal from THC and attenuation of withdrawal from THC. Experiment 1 evaluated acute and chronic AB-FUBINACA in the tetrad battery of tests. Experiment 2 evaluated precipitated withdrawal from AB-FUBINACA. Finally, Experiment 3 evaluated the effects of acute ZCZ011, a CB 1 positive allosteric modulator, and both of its enantiomers, and their ability attenuate the somatic signs of THC withdrawal.

3.1 Experiment 1: AB-FUBINACA induces classic cannabinoid effects. To evaluate the acute effects of AB-FUBINACA, male and female mice were injected with AB-FUBINACA $(0.1,1,2$, or $3 \mathrm{mg} / \mathrm{kg}$ ) or vehicle $30 \mathrm{~min}$ prior to testing. AB-FUBINACA ( $3 \mathrm{mg} / \mathrm{kg})$ increased latency in both catalepsy $[\mathrm{F}(4,32)=6.6, \mathrm{p}<.05 ;$ Fig. 3A $]$ and tail immersion $[\mathrm{F}(3,35)=6.9, \mathrm{p}<.05 ; \mathbf{F i g}$. 3B $]$ tests. Mice treated with AB-FUBINACA ( 2 or $3 \mathrm{mg} / \mathrm{kg}$ ) had decreased body temperature $[F(34,35)=24.9, p<.05$; Fig. 3C $]$ and increased time immobile $[F(4,35)=11.4, p<.05$; Fig. 3D $]$. The antinociceptive $(30 \mathrm{~min})$, cataleptic $(1 \mathrm{~h})$, and hypothermic $(2 \mathrm{~h})$ effects of AB-FUBINACA abated quickly [Fig.3E-G], as compared with the same effects of THC (50 mg/kg).

In a separate experiment, male and female mice were dosed twice daily with ABFUBINACA ( $3 \mathrm{mg} / \mathrm{kg}$ ) for 5 days and were tested daily in tetrad, to determine the degree to which AB-FUBINACA tolerance develops. Mice repeatedly administered AB-FUBINACA maintained increased latency in catalepsy [Main effect drug $F(1,70)=31.8, p<.05 ;$ Fig. 4A] antinociception [Main effect drug $\mathrm{F}(1,70)=15.3$,p<.05; Fig. 4B], and hypothermia despite 5 days of treatment [Main effect drug $\mathrm{F}(1,70)=121.5$,p<.05;Fig. 4C]. Similarly, when challenged with THC (50 mg/kg), mice treated with AB-FUBINACA for 5 days did not exhibit cross tolerance in catalepsy $[p=.48$; Fig. 4D], tail immersion $[p=.87 ;$ Fig. 4E], or body temperature $[p=.27 ; \mathbf{F i g}$. 4F]

In the final experiment, male and female mice were injected twice daily with $\mathrm{AB}$ FUBINACA ( 1 or $3 \mathrm{mg} / \mathrm{kg}$ ) for 5 days. On the $6^{\text {th }}$ day, mice were injected with AB-FUBINACA and were injected with rimonabant 30 min later and were immediately tested in somatic signs of withdrawal. When rimonabant was administered, AB-FUBINACA (1 mg/kg) treated mice exhibited increased paw tremors $[\mathrm{t}(18)=3.8, \mathrm{p}<.05 ;$ Fig. 4G] and head twitches 
$[\mathrm{t}(18)=3.0, \mathrm{p}<.05 ; \mathbf{F i g} . \mathbf{4 H}]$ compared to vehicle treated mice. Similarly, AB-FUBINACA (3 $\mathrm{mg} / \mathrm{kg}$ ) withdrawal increased both paw tremors $[\mathrm{F}(2,20)=9.7, \mathrm{p}<.05 ; \mathbf{F i g . 4 I}]$ and head twitches $[F(2,20)=4.3, p<.05 ;$ Fig.4J $]$. It is important to note that the rimonabant-precipitated somatic signs of withdrawal from AB-FUBINACA are of a smaller magnitude than those elicited by THC (10 or $50 \mathrm{mg} / \mathrm{kg}$ ) or JWH-018 (1 mg/kg) withdrawal (Trexler et al., 2018).

3.2 Experiment 2: Spontaneous THC withdrawal does not affect feeding. Because gastric issues are a commonly reported somatic sign of cannabinoid withdrawal, mice were trained to drink a sweetened condensed milk mixture and were treated twice daily for 6 days with either JWH-018 $(1 \mathrm{mg} / \mathrm{kg})$ or vehicle. Withdrawal was precipitated with rimonabant $(3 \mathrm{mg} / \mathrm{kg})$. Acute JWH-018 depressed drinking [Main effect of JWH-018 F(1,28)=279.3,p<.05; Fig. 5A], which returned to baseline levels by day 5 [p=.54], indicating tolerance had developed. Rimonabant, per se, significantly decreased feeding in both JWH-018 and vehicle treated mice Main effect of rimonabant $\mathrm{F}(1,28)=95.1, \mathrm{p}<.05]$. Thus, the spontaneous THC $(10$ or $50 \mathrm{mg} / \mathrm{kg})$ withdrawal model was used next. Both THC $(10 \mathrm{mg} / \mathrm{kg})$ and vehicle groups consumed the same baseline (training day 3)volume of milk $[\mathrm{p}=.53$; Fig. 5B] and THC-treated $(10 \mathrm{mg} / \mathrm{kg})$ mice returned to baseline consumption levels before testing [p=.19], indicating that THC tolerance developed. Mice were tested 12 and $36 \mathrm{~h}$ after the final THC (10 mg/kg) or vehicle injection. Both THC (10 $\mathrm{mg} / \mathrm{kg}$ ) and vehicle treated mice consumed the same amount on test day [p=.16], indicating that spontaneous THC has no effect on drinking.

Mice in both the THC and vehicle treated groups showed decreased in consumption following the injection of the first day of dosing. It is likely that this decrease was due to the stress of being injected. In a follow up experiment, the same experimental design was used, however, mice were injected with either vehicle or THC $(50 \mathrm{mg} / \mathrm{kg})$ twice daily. Mice were habituated to injections during training and vehicle-treated mice did not exhibit the same decrease in drinking on the first day of dosing. Again, THC treatment caused a decrease in drinking initially $[\mathrm{t}(6)=6.2, \mathrm{p}<.05$; Fig. 5C], and again, consumption returned to baseline by the $5^{\text {th }}$ day of dosing [p=.61]. As with THC (10 mg/kg), THC (50 mg/kg) spontaneous withdrawal did not cause a decrease in consumption relative to baseline at $12 \mathrm{~h}[\mathrm{p}=.24]$ or $36 \mathrm{~h}[\mathrm{p}=.70]$ abstinence. In this experiment, the vehicle treated mice had continually increasing consumption, making comparison between vehicle- and THC (50 mg/kg)-treated mice on test days misleading. 
3.3 Experiment 3a: Acute ZCZ011 does not have anxiolytic or anxiogenic effects. Cannabinoid orthosteric ligands, including THC, have anxiolytic properties. To determine possible anxiogenic or anxiolytic effects of ZCZ011, behavior was tested in the marble burying, light/dark box, open field, and novelty-induced hypophagia tests. Male mice were injected with ZCZ011 (2.5, 5, 10, 20 , or $40 \mathrm{mg} / \mathrm{kg}$ ) or vehicle $75 \mathrm{~min}$ prior to testing in marble burying. Treatment with ZCZ011 $(40 \mathrm{mg} / \mathrm{kg})$ decreased marbles buried $[\mathrm{F}(5,74)=14.0, \mathrm{p}<.05$; Fig. 6A], but also increased immobility $[\mathrm{F}(95,1273)=1.7, \mathrm{p}<.05$; Fig. 6B], indicating that ZCZ011-suppressed marble burying may reflect a broader decrease in activity in the assay. The lowest tested doses of ZCZ011 (i.e., 2.5 and $5 \mathrm{mg} / \mathrm{kg}$ ) did not produce any effects and were excluded from the following tests.

Male and female mice were injected with ZCZ011 (10, 20, or $40 \mathrm{mg} / \mathrm{kg}$, i.p.) or vehicle $75 \mathrm{~min}$ prior to testing in Light/Dark box. ZCZ011 (40 mg/kg) increased time in the dark compared to vehicle controls $[\mathrm{F}(3,44)=2.9, \mathrm{p}<.05$; Fig. 6C]. Similarly, mice treated with ZCZ011 (40 mg/kg) had increased immobility in the light/dark box $[F(3,44)=9.3$, p<.05; Fig. 6D]. In addition, male and female mice were injected with ZCZ011 (10, 20, or $40 \mathrm{mg} / \mathrm{kg}$, i.p.) or vehicle $75 \mathrm{~min}$ prior to testing in the Open field test. ZCZ011 (10, 20, or $40 \mathrm{mg} / \mathrm{kg})$ did not affect time spent in the center of the apparatus $[p=.39$; Fig. 6E] or time spent immobile $[p=.66$; Fig. 6F], but ZCZ011 (40 mg/kg) decreased number of rears $[F(3,44)=3.5, \mathrm{p}<.05 ;$ Fig. 6G].

Another group of male and female mice were trained to consume at least $1 \mathrm{~g}$ of a sweetened condensed milk mixture for 3 days prior to testing. Mice were injected with ZCZ011 $(10,20$, or $40 \mathrm{mg} / \mathrm{kg}$, i.p.) or vehicle $75 \mathrm{~min}$ prior to testing in either a dim light condition or an aversive condition in the presence or absence of ZCZ011, then in the opposite condition after 24 h. Drug treatment did not change across days. All mice consumed less milk in the aversive condition $[F(5,290)=61.36$, p<.05; Fig. 6H], and ZCZ011 (10, 20 or $40 \mathrm{mg} / \mathrm{kg})$ did not affect volume consumed in the aversive condition $[\mathrm{p}=.78]$. When retrained in the dim condition the following day, when no drug was administered, all mice, regardless of treatment or condition order, returned to baseline drinking levels [p=.99].

A separate group of male and female mice was injected with either of the ZCZ011 enantiomers, referred to here as "ZCZ011A" or "ZCZ011B", and was tested in open field and marble burying tests. Neither compound affected time in the center of the open field $[\mathrm{p}=.08 ;$ Fig. 
7A], time immobile in open field [p=.06;Fig 7B], or rearing (an exploratory behavior) in the open field test $[p=.79 ;$ Fig. 7C $]$. Neither enantiomer affected marbles buried $[p=.20 ;$ Fig. 7D], but ZCZ011A increased time immobile $[\mathrm{F}(2,33)=5.9, \mathrm{p}<.05$; Fig. 7E $]$.

3.4 Experiment 3b: Somatic signs of THC withdrawal attenuated by ZCZ011. ZCZ011 (10 or 40 $\mathrm{mg} / \mathrm{kg}$ ) attenuates somatic signs of THC withdrawal (Trexler et al., 2019). To determine whether ZCZ011 also attenuates withdrawal-induced changes in marble burying and tail suspension, mice were subjected to the rimonabant-precipitated THC withdrawal paradigm and injected with ZCZ011 (10 or $40 \mathrm{mg} / \mathrm{kg}$ ) or vehicle $75 \mathrm{~min}$ prior to testing. ZCZ011 (10 or $40 \mathrm{mg} / \mathrm{kg}$ ) did not attenuate THC withdrawal-suppressed marble burying $[\mathrm{F}(2,42)=12.2, \mathrm{p}<.05 ;$ Fig. 8A $]$ or withdrawal-induced struggling in the tail suspension test [Main effect THC $[F(1,42)=89.4, p<.05 ; F i g .8 B]$. As in Exp. 3.3, ZCZ011 alone $(40 \mathrm{mg} / \mathrm{kg})$ increased immobility in marble burying [Main effect ZCZ011 [F (2,42)= 7.3,p<.05; Fig. 8C]. Surprisingly, but ZCZ011 $(\geq 10 \mathrm{mg} / \mathrm{kg}$ ) increased immobility in mice subjected to precipitated THC withdrawal.

To determine ZCZ011 dose-dependent effects on attenuating somatic signs of withdrawal, mice were subjected to precipitated THC withdrawal, and injected with ZCZ011 (1, 3.33 , or $10 \mathrm{mg} / \mathrm{kg}$ ) or vehicle. ZCZ011 $(10 \mathrm{mg} / \mathrm{kg})$ reduced both paw tremors $[F(4,32)=6.8, p<.05 ; F i g .8 D]$ and head twitches $[F(4,32)=4.5, p<.05 ;$ Fig.8E $]$. Posts hoc analyses revealed that ZCZ011 $(3.33 \mathrm{mg} / \mathrm{kg})$ attenuated head twitches but had no effect on paw tremors.

The ability of the two enantiomers of ZCZ011, i.e., ZCZ011A and ZCZ011B, to attenuate precipitated THC withdrawal was evaluated. Mice were subjected with precipitated THC withdrawal and treated with ZCZ011 A or ZCZ011B $(0.55,1.66$, or $5 \mathrm{mg} / \mathrm{kg})$ or vehicle $75 \mathrm{~min}$ prior to testing. Either ZCZ011A or ZCZ011B ( $5 \mathrm{mg} / \mathrm{kg}$ ) attenuated paw tremors $[F(4,35)=16.7, p<.05 ;$ Fig.8F $]$ and head twitches $[F(4,35)=10.8, p<.05 ;$ Fig.8G $]$. Neither ZCZ011A nor ZCZ011B $(0.55$ or $1.66 \mathrm{mg} / \mathrm{kg})$ affected paw tremors [p=.28; Fig. $\mathbf{8 H}$ ] or head twitches $[\mathrm{p}=.20$; Fig. 8I $]$.

\section{Discussion}

The current project was designed to evaluate the acute and chronic effects of the synthetic cannabinoid AB-FUBINACA. It also evaluated the development of tolerance to and withdrawal from AB-FUBINACA. Additionally, sweetened condensed milk consumption was evaluated as a 
potential new assay of spontaneous THC withdrawal. Finally, the acute anxiolytic effects of ZCZ011 and its enantiomers was probed and ZCZ011 and its enantiomers were further evaluated as a method of attenuating precipitated THC withdrawal.

AB-FUBINACA produced classic cannabinoid effects, including catalepsy, antinociception, hypothermia, and hypolocomotion. Surprisingly, AB-FUBINACA has a significantly shorter timecourse than THC and previous generation synthetic cannabinoids. While a rapid onset, similar to the one observed here, has been reported previously, the tetrad effects in the present study abated more quickly than previously reported (Banister, Moir, et al., 2015; Kevin et al., 2017). It is plausible that the differences in observed effect timecourse and magnitude are due to a species difference, as the previous studies were carried out in rats. Regardless, the rapid onset and relatively short timecourse are similar to those seen with other third-generation synthetic cannabinoids, including AB-CHMINACA delivered via inhalation (Lefever et al., 2017). A likely mechanism for the relatively quick recovery from these compounds is rapid metabolism. Previous studies have demonstrated that synthetic cannabinoids tend to be rapidly metabolized, and that more or less potent metabolites remain in the organism interacting with cannabinoid receptors (Brents et al., 2012). It has been further suggested that an alternate route of administration (e.g., inhalation) may be a better model of synthetic cannabinoid use because these compounds are generally administered in vapor (Lefever et al., 2017), which most closely resembles intravenous administration with regard to speed of delivery to brain. Moreover, the rapid timecourse of new generation drugs is even further accelerated in an inhaled aerosol model (Lefever et al., 2017). Regardless, the relatively short timecourse of ABFUBINACA reported here is novel and evident following intraperitoneal administration.

The lack of tolerance to AB-FUBINACA in the current experiments is in some ways surprising, as the dosing regimen is adequate to produce tolerance to both THC and other synthetic cannabinoids, like WIN55-212 and JWH-018 (Aceto et al., 2001; Lichtman, Fisher, \& Martin, 2001; Schlosburg et al., 2009; Trexler et al., 2018). Additionally, AB-FUBINACA is a full $\mathrm{CB}_{1}$ agonist with higher potency than THC (Hess et al., 2016; Wiley et al., 2015). Thus, we expected tolerance to develop at the same rate, or perhaps even earlier, than with THC. However, the rapid timecourse of AB-FUBINACA metabolism may render the current dosing paradigm ineffective. Thus, it is plausible that, for tolerance to fully develop, mice must be dosed more 
frequently, or perhaps ideally administered continuously, for example via osmotic minipump. But, such an approach has limited construct validity and does not reflect patterns of human cannabinoid self-administration. Regardless, the small effect of precipitated AB-FUBINACA withdrawal is not surprising, given the observed lack of tolerance in the tetrad battery. It was also expected that, given its relatively higher potency, AB-FUBINACA withdrawal would be of the same or perhaps larger magnitude than that of THC, but the observed withdrawal effects, while statistically significant, were relatively minor. This issue may also be resolved by adjusting the dosing regimen as outlined above, or perhaps other behavioral assays will reveal subtleties in AB-FUBINACA withdrawal that were not detectable with the present assays.

Generally, AB-FUBINACA exhibited cannabimimetic effects in the tetrad battery of assays, but has a much faster time course. To further explore the effects of AB-FUBINACA, future studies should include components evaluating brain, plasma, or urine analysis for metabolites of the drug over time. I anticipate that AB-FUBINACA is rapidly metabolized in vivo, and that patterns of brain levels will mirror those of the behavioral assays reported on here. Additional studies that challenge the effects of AB-FUBINACA, for example with the $\mathrm{CB}_{1}$ inverse agonist rimonabant, will also be useful in determining whether all of the effects observed were $\mathrm{CB}_{1}$ mediated, or if $\mathrm{AB}-\mathrm{FUBINACA}$ is acting, at least in part, through cannabinoid receptor independent mechanisms.

Due to the small effect of precipitated AB-FUBINACA withdrawal, THC was used to pilot the possible effects of cannabinoid withdrawal on sweetened condensed milk consumption. We evaluated spontaneous THC withdrawal effects on sweetened condensed milk consumption, a common anhedonia model. We chose a spontaneous withdrawal paradigm, because pilot data (Fig 5A) indicated that rimonabant, per se, suppresses drinking. In the present study, spontaneous THC withdrawal was evaluated $36 \mathrm{~h}$ after the final THC injection. This $36 \mathrm{~h}$ timepoint was selected because we have previously reported "peak" withdrawal signs at $36 \mathrm{~h}$ THC abstinence (Trexler et al., 2018). I hypothesized that mice would exhibit decreased sweetened condensed milk consumption during spontaneous withdrawal, but this effect was not observed. Given the lack of an effect of THC withdrawal, we chose not to test spontaneous ABFUBINACA withdrawal in this model. Because somatic signs of precipitated AB-FUBINACA withdrawal (i.e., Exp 2a) were of surprisingly small magnitude, and that effects of spontaneous 
withdrawal are typically of a smaller magnitude than precipitated withdrawal models (Aceto et al., 2001; Trexler, Eckard, \& Kinsey, 2019; Trexler et al., 2018), we concluded that spontaneous AB-FUBINACA withdrawal effects on sweetened condensed milk consumption are unlikely to be observed.

In addition to measuring feeding behavior, sweetened milk drinking was chosen in this study because of its use in evaluating depressive-like effects (i.e., anhedonia), which humans frequently report as a symptom of cannabis withdrawal (American Psychiatric Association, 2013). Because of the differences in type of symptomology (i.e, somatic symptoms versus emotionality-related symptoms), it is plausible that the onset of different behavioral changes occur at different times. For example, we have previously reported that both precipitated and spontaneous THC withdrawal increase struggling in the tail suspension test (Trexler et al., 2018). Coincident with spontaneous somatic withdrawal signs, the increase in struggling is evident at 36 $\mathrm{h}$ abstinence. Thus, although we did not observe altered drinking at 12 or $36 \mathrm{~h}$ abstinence, expending the number of time points of sampling may reveal a withdrawal time course in this assay that differs from other models. Another approach would be to increase THC dosing, perhaps to $50 \mathrm{mg} / \mathrm{kg}$ twice daily, with the goal of increasing withdrawal effects. Although we have not observed differences between 10 and $50 \mathrm{mg} / \mathrm{kg}$ THC in somatic signs of withdrawal or tail suspension tests (Trexler et al., 2018), it is plausible that feeding is sensitive to such differences in dosing.

Acute ZCZ011 was evaluated in several anxiety-related assays because increased activity of the endocannabinoid system has anxiolytic effects (Kinsey, O’Neal, Long, Cravatt, \& Lichtman, 2011; Moreira, Grieb, \& Lutz, 2009). ZCZ011 decreased marble burying and decreased rearing in the open field test, which would typically be interpreted as an anxiolytic drug profile. In the light/dark box test, however, ZCZ011 increased time spent in the dark, which would typically be interpreted as an anxiogenic effect. But, the same dose of ZCZ011 (40 mg/kg) also elicited locomotor effects in both the marble burying and light/dark box tests, indicating that the decrease in marbles buried and increased time in the dark were likely due to sedative effects. This effect contrasts with findings showing the same dose of ZCZ011 does not produce locomotor suppression the spontaneous locomotor test (Ignatowska-Jankowska et al., 2015; Trexler et al., 2019). The light/dark box test relies on creating a conflict paradigm to evaluate 
anxiety-like behavior (Crawley, 2007) and the marble burying test also been implicated as a stress-inducing paradigm (Abraham et al., 2018), so it is plausible that the locomotor effects of ZCZ011 are only observed in stressful or aversive conditions, which would not include the apparatus used in a spontaneous locomotor assessment. Thus, the assay dependent locomotor effects observed may be compounded by stress responsiveness.

Both enantiomers of ZCZ011, ZCZ011A and ZCZ011B, were evaluated independently in marble burying and open field assays. ZCZ011A caused decreased locomotion in the marble burying task, but did not cause a statistically significant reduction in number of marbles buried. We found no effects of either enantiomer in open field, which is consistent with the lack of effect of ZCZ011 in open field. The locomotor deficits observed in the marble burying and light/dark box tests are the result of ZCZ011A, rather than ZCZ011B, as evidenced by the locomotor deficit associated with ZCZ011A in the marble burying test. Future studies evaluating dose dependent effects of the individual enantiomers and evaluation in the light/dark box assay are needed to determine relative contributions of each enantiomer.

Precipitated THC withdrawal was challenged with ZCZ011 in the marble burying and tail suspension tests. Interestingly, precipitated withdrawal-depressed marble burying and increased tail suspension struggling were not attenuated by ZCZ011 (10 and $40 \mathrm{mg} / \mathrm{kg})$, which is similar to previous findings using the MAGL inhibitor JZL184 (Trexler et al., 2018), which increases brain levels of 2-AG by preventing its catabolism. Both ZCZ011 and JZL184 attenuate both precipitated and spontaneous somatic signs of withdrawal, but neither drug reverses withdrawaldepressed marble burying or withdrawal-induced increases in struggling in the tail suspension test. Plasma levels of the stress hormone corticosterone increase during THC withdrawal, and the endocannabinoid system and stress circuitry are closely related (Hill \& Gorzalka, 2005; Oliva et al., 2004; Patel, Roelke, Rademacher, \& Hillard, 2005; Trexler et al., 2018). Thus, the decrease in marble burying and increase in struggling during THC withdrawal may be related to altered regulation of the hypothalamic-pituitary-adrenal (HPA) axis stress circuit caused by repeated $\mathrm{CB}_{1}$ activation. Interestingly, these effects are not attenuated by administration of a glucocorticoid antagonist, mifepristone, or a $\beta$-adrenergic antagonist, propranolol, indicating the effect is likely not mediated through those mechanisms (Trexler et al., 2018). Thus, future studies should target corticotrophin releasing factor as a stress mechanism that mediates the emotionality-related behavioral effects of cannabinoid withdrawal. 
ZCZ011 attenuated somatic signs of THC withdrawal in a dose dependent manner. The lowest dose tested, $1 \mathrm{mg} / \mathrm{kg}$, did not attenuate paw tremors or head twitches, and the moderate dose, $3 \mathrm{mg} / \mathrm{kg}$, attenuated head twitches, but not paw tremors, and the highest dose tested, 10 $\mathrm{mg} / \mathrm{kg}$, attenuated both paw tremors and head twitches, as previously published (Trexler et al., 2019). It is noteworthy that, no locomotor effects of $10 \mathrm{mg} / \mathrm{kg}$ ZCZ011 are observed in any assays, which rules out possible sedative confounds. $\mathrm{CB}_{1}$ positive allosteric modulation is a relatively new area, but several PAMs have already shown demonstrated their anti-nociceptive, anti-inflammatory, and gastroprotective properties (Ignatowska-Jankowska et al., 2015; Slivicki et al., 2017; Trexler et al., 2019), so this approach has been fruitful, albeit using different endogenous target receptor systems. Further, the finding that either enantiomer of ZCZ011 attenuates somatic signs of withdrawal is promising. Moreover, ZCZ011B not only attenuates withdrawal, but does so with no locomotor effects of its own. Taken together, the present data indicate that ZCZ011B, or a novel compound with similar properties, shows early promise as an option for development as a therapeutic agent to treat cannabis use disorder.

\section{Conclusion}

The present studies revealed that AB-FUBINACA, a third-generation synthetic cannabinoid, has cannabimimetic effects that abate much more rapidly than the traditional phytocannabinoid, THC. Future studies into its metabolism will help to further understand the differences between AB-FUBINACA and THC. As human use of synthetic cannabinoids continues it will be increasingly important to use the information gained from experimental study to inform treatments for synthetic cannabinoids. Though spontaneous THC withdrawal is reliably observed in somatic and tail suspension models, it was undetectable in an anhedonia model. The exploration of additional timepoints may reveal that in the anhedonia model, THC withdrawal peaks at a different time. Finally, ZCZ011 has few acute effects on its own, and the effects it does have are likely driven by sedative effects, which appear to be caused entirely by one enantiomer, ZCZ011A. Further, ZCZ011 and each of its enantiomers attenuate THC withdrawal in a somatic model at doses that do not produce sedative effects. ZCZ011B may also be a therapeutic agent due to its ability to attenuate withdrawal and its lack of acute locomotor effects. Regardless of the individual contributions of either enantiomer, these data provide proof-of- 
concept that $\mathrm{CB}_{1}$ positive allosteric modulation is a viable strategy for reducing cannabis use disorder. 


\section{References}

Abraham, A. D., Fontaine, H. M., Song, A. J., Andrews, M. M., Baird, M. A., Kieffer, B. L., ... Chavkin, C. (2018). $\kappa$-Opioid Receptor Activation in Dopamine Neurons Disrupts Behavioral Inhibition. Neuropsychopharmacology, 43, 362-372. https://doi.org/10.1038/npp.2017.133

Aceto, M., Scates, S., \& Martin, B. (2001). Spontaneous and precipitated withdrawal with a synthetic cannabinoid, WIN 55212-2. European Journal of Pharmacology, 416, 75-81. https://doi.org/10.1016/S0014-2999(01)00873-1

Adams, A. J., Banister, S. D., Irizarry, L., Trecki, J., Schwartz, M., \& Gerona, R. (2017). "Zombie" Outbreak Caused by the Synthetic Cannabinoid AMB-FUBINACA in New York. New England Journal of Medicine, 376(3), 235-242. https://doi.org/10.1056/NEJMoa1610300

Allsop, D. J., Lintzeris, N., Copeland, J., Dunlop, A., \& McGregor, I. S. (2015). Cannabinoid Replacement Therapy (CRT): Nabiximols (Sativex) as a novel treatment for cannabis withdrawal. Clin Pharmacol Ther, 97(6), 571-574. https://doi.org/10.1002/cpt.109

American Association of Poison Control Centers: Synthetic Cannabinoids. (2018). Retrieved from https://www.aapcc.org/track/synthetic-cannabinoids

American Psychiatric Association. (2013). Diagnostic and Statistical Manual of Mental Health Disorders (5th ed.). Washington, D.C.

Bailey, M. T., Kinsey, S. G., Padgett, D. A., Sheridan, J. F., \& Leblebicioglu, B. (2009). Social stress enhances IL-1 $\beta$ and TNF- $\alpha$ production by Porphyromonas gingivalis lipopolysaccharide-stimulated CD11b+ cells. Physiology and Behavior, 98(3), 351-358. https://doi.org/10.1016/j.physbeh.2009.06.013

Banister, S. D., Moir, M., Stuart, J., Kevin, R. C., Wood, K. E., Longworth, M., ... Kassiou, M. (2015). Pharmacology of Indole and Indazole Synthetic Cannabinoid Designer Drugs ABFUBINACA, ADB-FUBINACA, AB-PINACA, ADB-PINACA, 5F-AB-PINACA, 5FADB-PINACA, ADBICA, and 5F-ADBICA. ACS Chemical Neuroscience, 6(9), 15461559. https://doi.org/10.1021/acschemneuro.5b00112

Banister, S. D., Stuart, J., Kevin, R. C., Edington, A., Longworth, M., Wilkinson, S. M., ... Kassiou, M. (2015). Effects of Bioisosteric Fluorine in Synthetic Cannabinoid Designer Drugs JWH-018, AM-2201, UR-144, XLR-11, PB-22, 5F-PB-22, APICA, and STS-135. ACS Chemical Neuroscience, 6(8), 1445-1458. https://doi.org/10.1021/acschemneuro.5b00107

Benford, D. M., \& Caplan, J. P. (2011). Psychiatric Sequelae of Spice, K2, and Synthetic Cannabinoid Receptor Agonists. Psychosomatics, 52(3), 295. https://doi.org/10.1016/j.psym.2011.01.004

Besli, G. E., Ikiz, M. A., Yildirim, S., \& Saltik, S. (2015). Synthetic Cannabinoid Abuse in Adolescents: A Case Series. Journal of Emergency Medicine, 49(5), 644-650. https://doi.org/10.1016/j.jemermed.2015.06.053

Bhanushali, G. K., Jain, G., Fatima, H., Leisch, L. J., \& Thornley-Brown, D. (2013). AKI 
associated with synthetic cannabinoids: A case series. Clinical Journal of the American Society of Nephrology, 8(4), 523-526. https://doi.org/10.2215/CJN.05690612

Blankman, J. L., Simon, G. M., \& Cravatt, B. F. (2007). A Comprehensive Profile of Brain Enzymes that Hydrolyze the Endocannabinoid 2-Arachidonoylglycerol. Chemistry \& Biology, 14(12), 1347-1356. https://doi.org/10.1016/j.chembiol.2007.11.006

Brents, L K, Zimmerman, S. M., Saffell, A. R., Prather, P. L., \& Fantegrossi, W. E. (2013). Differential drug-drug interactions of the synthetic Cannabinoids JWH-018 and JWH-073: implications for drug abuse liability and pain therapy. J Pharmacol Exp Ther, 346(3), 350361. https://doi.org/10.1124/jpet.113.206003

Brents, Lisa K., Gallus-Zawada, A., Radominska-Pandya, A., Vasiljevik, T., Prisinzano, T. E., Fantegrossi, W. E., ... Prather, P. L. (2012). Monohydroxylated metabolites of the K2 synthetic cannabinoid JWH-073 retain intermediate to high cannabinoid 1 receptor (CB1R) affinity and exhibit neutral antagonist to partial agonist activity. Biochemical Pharmacology, 83(7), 952-961. https://doi.org/10.1016/j.bcp.2012.01.004

Brezing, C. A., \& Levin, F. R. (2017). The Current State of Pharmacological Treatments for Cannabis Use Disorder and Withdrawal. Neuropsychopharmacology, (April), 1-71. https://doi.org/10.1038/npp.2017.212

Broekkamp, C. L., Rijk, H. W., Joly-gelouin, D., \& Lloyd, K. L. (1986). Major tranquillizers can be distinguished from minor tranquillizers on the basis of effects on marble burying and swim-induced grooming in mice. European Journal of Pharmacology, 126, 223-229.

Budney, A. J., Vandrey, R. G., Hughes, J. R., Moore, B. a, \& Bahrenburg, B. (2007). Oral delta9-tetrahydrocannabinol suppresses cannabis withdrawal symptoms. Drug and Alcohol Dependence, 86, 22-29. https://doi.org/10.1016/j.drugalcdep.2006.04.014

Budney, A. J., Vandrey, R. G., Hughes, J. R., Thostenson, J. D., \& Bursac, Z. (2008). Comparison of cannabis and tobacco withdrawal: Severity and contribution to relapse. Journal of Substance Abuse Treatment, 35(4), 362-368. https://doi.org/10.1016/j.jsat.2008.01.002

Burford, N. T., Traynor, J. R., \& Alt, A. (2015). Positive allosteric modulators of the $\mu$-opioid receptor: A novel approach for future pain medications. British Journal of Pharmacology, 172, 277-286. https://doi.org/10.1111/bph.12599

Canazza, I., Ossato, A., Trapella, C., Fantinati, A., De Luca, M. A., Margiani, G., .. Marti, M. (2016). Effect of the novel synthetic cannabinoids AKB48 and 5F-AKB48 on "tetrad", sensorimotor, neurological and neurochemical responses in mice. In vitro and in vivo pharmacological studies. Psychopharmacology, 233(21-22), 3685-3709. https://doi.org/10.1007/s00213-016-4402-y

Carlier, J., Wohlfarth, A., Salmeron, B. D., Scheidweiler, K. B., Huestis, M. A., \& Baumann, M. H. (2018). Pharmacodynamic Effects, Pharmacokinetics, and Metabolism of the Synthetic Cannabinoid AM-2201 in Male Rats. The Journal of Pharmacology and Experimental Therapeutics, 367(December), 543-550. https://doi.org/10.1124/jpet.118.250530

Castaneto, M. S., Gorelick, D. A., Desrosiers, N. A., Hartman, R. L., Pirard, S., \& Huestis, M. A. 
(2014). Synthetic cannabinoids: Epidemiology, pharmacodynamics, and clinical implications. Drug and Alcohol Dependence, 144, 12-41.

https://doi.org/10.1016/j.drugalcdep.2014.08.005

Chan, W. L., Wood, D. M., Hudson, S., \& Dargan, P. I. (2013). Acute Psychosis Associated with Recreational Use of Benzofuran 6- ( 2-Aminopropyl ) Benzofuran ( 6-APB ) and Cannabis. J. Med. Toxicol, (9), 278-281. https://doi.org/10.1007/s13181-013-0306-y

Chase, P. B., Hawkins, J., Mosier, J., Jimenez, E., Boesen, K., Logan, B. K., \& Walter, F. G. (2016). Differential physiological and behavioral cues observed in individuals smoking botanical marijuana versus synthetic cannabinoid drugs. Clinical Toxicology, 54(1), 14-19. https://doi.org/10.1111/jzs.12127

Chimalakonda, K. C., Seely, K. A., Bratton, S. M., Brents, L. K., Moran, C. L., Endres, G. W., ... Moran, J. H. (2012). Cytochrome P450-mediated oxidative metabolism of abused synthetic cannabinoids found in K2/Spice: Identification of novel cannabinoid receptor ligands. Drug Metabolism and Disposition, 40(11), 2174-2184. https://doi.org/10.1124/dmd.112.047530

Chinnadurai, T., Shrestha, S., \& Ayinla, R. (2016). A curious case of inhalation fever caused by synthetic cannabinoid. American Journal of Case Reports, 17, 379-383. https://doi.org/10.12659/AJCR.898500

Clark, B. C., Georgekutty, J., \& Berul, C. I. (2015). Myocardial Ischemia Secondary to Synthetic Cannabinoid (K2) Use in Pediatric Patients. Journal of Pediatrics, 167(3), 757-761.e1. https://doi.org/10.1016/j.jpeds.2015.06.001

Cooper, Z. D. (2016). Adverse Effects of Synthetic Cannabinoids: Management of Acute Toxicity and Withdrawal. Curr Psychiatry Rep, 18(5). https://doi.org/10.1161/CIRCRESAHA.116.303790.The

Cravatt, B. F., Giang, D. K., Mayfield, S. P., Boger, D. L., Lerner, R. A., \& Gilula, N. B. (1996). Molecular characterization of an enzyme that degrades neuromodulatory fatty-acid amides. Nature, 384, 83-87.

Crawley, J., \& Goodwin, F. K. (1980). Preliminary Report of a Simple Animal Behavior Model for the Anxiolytic Effects of Benzodiazepines, 13, 167-170.

Crawley, J. N. (2007). Mouse behavioral assays relevant to the symptoms of autism. Brain Pathology, 17(4), 448-459. https://doi.org/10.1111/j.1750-3639.2007.00096.x

Davidson, C., Opacka-Juffry, J., Arevalo-Martin, A., Garcia-Ovejero, D., Molina-Holgado, E., \& Molina-Holgado, F. (2017). Spicing Up Pharmacology: A Review of Synthetic Cannabinoids From Structure to Adverse Events. Advances in Pharmacology (1st ed., Vol. 80). Elsevier Inc. https://doi.org/10.1016/bs.apha.2017.05.001

de Havenon, A., Chin, B., Thomas, K. C., \& Afra, P. (2011). The Secret "Spice": An Undetectable Toxic Cause of Seizure. The Neurohospitalist, 1(4), 182-186. https://doi.org/10.1177/1941874411417977

Deadwyler, S., Hampson, R., Mu, J., Whyte, A., \& Childers, S. (1995). Cannabinoids in Hippocampal Modulate Voltage Sensitive Potassium Neurons Via a cAMP-Dependent. 
Journal of Pharmacology and Experimental Therapeutics, 273(2), 734-743.

Devane, W., Hanus, L., Breuer, A., Pertwee, R. G., Stevenson, L. A., Graeme, G., ... Mechoulam, R. (1992). Isolation and Structure of a brain constituent that binds to the cannabinoid receptor.

Di Marzo, V. (2009). The endocannabinoid system: Its general strategy of action, tools for its pharmacological manipulation and potential therapeutic exploitation. Pharmacological Research, 60(2), 77-84. https://doi.org/10.1016/j.phrs.2009.02.010

Diao, X., Scheidweiler, K. B., Wohlfarth, A., Pang, S., Kronstrand, R., \& Huestis, M. A. (2016). In Vitro and In Vivo Human Metabolism of Synthetic Cannabinoids FDU-PB-22 and FUBPB-22. The AAPS Journal, 18(2). https://doi.org/10.1208/s12248-016-9867-4

Dresen, S., Ferreirós, N., Pütz, M., Westphal, F., Zimmermann, R., \& Auwärter, V. (2010). Monitoring of herbal mixtures potentially containing synthetic cannabinoids as psychoactive compounds. Journal of Mass Spectrometry, 45(10), 1186-1194. https://doi.org/10.1002/jms.1811

Durand, D., Delgado, L. L., Parra-Pellot, D. M. de la, \& Nichols-Vinueza, D. (2015). Psychosis and Severe Rhabdomyolysis Associated with Synthetic Cannabinoid Use. Clinical Schizophrenia \& Related Psychoses, 8(4), 205-208. https://doi.org/10.3371/CSRP.DUDE.031513

El Khoury, M. A., Gorgievski, V., Moutsimilli, L., Giros, B., \& Tzavara, E. T. (2012). Interactions between the cannabinoid and dopaminergic systems: Evidence from animal studies. Progress in Neuro-Psychopharmacology and Biological Psychiatry, 38(1), 36-50. https://doi.org/10.1016/j.pnpbp.2011.12.005

EMCDDA. (2009). European Monitoring Centre of Drugs and Drugs addiction. The state of the drugs problem in Europe. Annual report 2009.

Erratico, C., Negreira, N., Norouzizadeh, H., Covaci, A., Neels, H., Maudens, K., \& van Nuijs, A. L. N. (2015). In vitro and in vivo human metabolism of the synthetic cannabinoid ABCHMINACA. Drug Testing and Analysis, 7(10), 866-876. https://doi.org/10.1002/dta.1796

Falenski, K. W., Thorpe, A. J., Schlosburg, J. E., Cravatt, B. F., Abdullah, R. A., Smith, T. H., ... Sim-Selley, L. J. (2010). FAAH-/- Mice Display Differential Tolerance, Dependence, and Cannabinoid Receptor Adaptation After $\Delta 9$-Tetrahydrocannabinol and Anandamide Administration. Neuropsychopharmacology, 35(8), 1775-1787. https://doi.org/10.1038/npp.2010.44

Fantegrossi, W. E., Moran, J. H., Radominska-pandya, A., \& Prather, P. L. (2014). Distinct pharmacology and metabolism of K2 synthetic cannabinoids compared to $\triangle 9$-THC: Mechanism underlying greater toxicity? Life Sciences, 97(1), 45-54. https://doi.org/10.1016/j.lfs.2013.09.017

Fantegrossi, W. E., Wilson, C. D., \& Berquist, M. D. (2018). Pro-psychotic effects of synthetic cannabinoids: interactions with central dopamine, serotonin, and glutamate systems. Drug Metabolism Reviews, 50(1), 65-73. https://doi.org/10.1080/03602532.2018.1428343

Finn, D. P. (2010). Endocannabinoid-mediated modulation of stress responses: Physiological and 
pathophysiological significance. Immunobiology, 215(8), 629-646.

https://doi.org/10.1016/j.imbio.2009.05.011

Fisar, Z. (2009). Phytocannabinoids and endocannabinoids. Current Drug Abuse Reviews, 2(October), 51-75. https://doi.org/10.2174/1874473710902010051

Flores, Á., Maldonado, R., \& Berrendero, F. (2013). Cannabinoid-hypocretin cross-talk in the central nervous system: What we know so far. Frontiers in Neuroscience, 7(7 DEC), 1-17. https://doi.org/10.3389/fnins.2013.00256

Ford, B. M., Tai, S., Fantegrossi, W. E., \& Prather, P. L. (2017). Synthetic Pot: Not Your Grandfather's Marijuana. Trends in Pharmacological Sciences, 38(3), 257-276. https://doi.org/10.1016/j.tips.2016.12.003

Franklin, J. M., \& Carrasco, G. A. (2012). Cannabinoid-induced enhanced interaction and protein levels of serotonin 5-HT2A and dopamine D2 receptors in rat prefrontal cortex. Journal of Psychopharmacology, 26(10), 1333-1347. https://doi.org/10.1177/0269881112450786

Freund, T. F., Katona, I., \& Piomelli, D. (2003). Role of endogenous cannabinoids in synaptic signaling. Physiological Reviews, 83(3), 1017-1066. https://doi.org/10.1152/physrev.00004.2003

Frinculescu, A., Lyall, C. L., Ramsey, J., \& Miserez, B. (2017). Variation in commercial smoking mixtures containing third-generation synthetic cannabinoids. Drug Testing and Analysis, 9(2), 327-333. https://doi.org/10.1002/dta.1975

Gamble-George, J. C., Conger, J. R., Hartley, N. D., Gupta, P., Sumislawski, J. J., \& Patel, S. (2013). Dissociable effects of CB1 receptor blockade on anxiety-like and consummatory behaviors in the novelty-induced hypophagia test in mice. Psychopharmacology, 228, 401409. https://doi.org/10.1007/s00213-013-3042-8

Gaoni, Y., \& Mechoulam, R. (1964). Isolation, structure, and partial synthesis of an active constituent of hashish. Journal of the American Chemical ..., 86, 1646-1647. https://doi.org/10.1021/ja01062a046

Gatch, M. B., \& Forster, M. J. (2015). 9 -Tetrahydrocannabinol-Like Effects of Novel Synthetic Cannabinoids Found on the Gray Market Michael. Behavioral Pharmacology, 26(5), 460468. https://doi.org/10.1097/FBP.0000000000000150.

Gay, M. (2010). Synthetic Marijuana Spurs State Bans. The New York Times, 2-5. Retrieved from http://www.nytimes.com/2010/07/11/us/11k2.html?_r=1

Haney, M., Bedi, G., Cooper, Z. D., Glass, A., Vosburg, S. K., Comer, S. D., \& Foltin, R. W. (2013). Predictors of marijuana relapse in the human laboratory: Robust impact of tobacco cigarette smoking status. Biological Psychiatry, 73(3), 242-248. https://doi.org/10.1016/j.biopsych.2012.07.028

Haney, M., Hart, C. L., Vosburg, S. K., Comer, S. D., Reed, S. C., \& Foltin, R. W. (2008). Effects of THC and Lofexidine in a Human Laboratory Model of Marijuana Withdrawal and Relapse. Psychopharmacology (Berl), 197(1), 157-168. https://doi.org/10.2217/nnm.12.167.Gene 
Haney, M., Hart, C. L., Vosburg, S. K., Nasser, J., Bennett, A., Zubaran, C., \& Foltin, R. W. (2004). Marijuana Withdrawal in Humans: Effects of Oral THC or Divalproex. Neuropsychopharmacology, 29(1), 158-170. https://doi.org/10.1038/sj.npp.1300310

Hartman, R. L., \& Huestis, M. A. (2013). Cannabis effects on driving skills. Clinical Chemistry, 59(3), 478-492. https://doi.org/10.1373/clinchem.2012.194381

Hasin, D. S., Kerridge, B. T., Saha, T. D., Huang, B., Pickering, R., Smith, S. M., ... Grant, B. F. (2016). Prevalence and correlates of DSM-5 cannabis use disorder, 2012-2013: Findings from the national epidemiologic survey on alcohol and related conditions-III. American Journal of Psychiatry, 173(6), 588-599. https://doi.org/10.1176/appi.ajp.2015.15070907

Hess, C., Schoeder, C. T., Pillaiyar, T., Madea, B., \& Müller, C. E. (2016). Pharmacological evaluation of synthetic cannabinoids identified as constituents of spice. Forensic Toxicology, 34(2), 329-343. https://doi.org/10.1007/s11419-016-0320-2

Hill, M. N., \& Gorzalka, B. B. (2005). Is there a role for the endocannabinoid system in the etiology and treatment of melancholic depression? Behavioural Pharmacology, 16, 333352. https://doi.org/10.1097/00008877-200509000-00006

Howlett, A. C. (1985). Cannabinoid Biochemistry Inhibition of Adenylate in Neuroblastoma Cyclase Cell Membranes of the Response. Molecular Pharmacology, 27, 429-436.

Howlett, A. C. (2005). Cannabinoid Receptor Signaling. In Cannabinoids (pp. 53-79).

Hudson, S., \& Ramsey, J. (2011). The emergence and analysis of synthetic cannabinoids. Drug Testing and Analysis, 3(7-8), 466-478. https://doi.org/10.1002/dta.268

Huestis, M. A. (2007). Human cannabinoid pharmacokinetics. Chemistry and Biodiversity, 4, 1770-1804. https://doi.org/10.1002/cbdv.200790152

Huffman, J. W., Zengin, G., Wu, M. J., Lu, J., Hynd, G., Bushell, K., .. Martin, B. R. (2005). Structure-activity relationships for 1-alkyl-3-(1-naphthoyl)indoles at the cannabinoid CB1 and CB2receptors: Steric and electronic effects of naphthoyl substituents. New highly selective CB2receptor agonists. Bioorganic and Medicinal Chemistry, 13(1), 89-112. https://doi.org/10.1016/j.bmc.2004.09.050

Ignatowska-Jankowska, B. M., Baillie, G. L., Kinsey, S., Crowe, M., Ghosh, S., Owens, R. A., ... Ross, R. A. (2015). A Cannabinoid CB1 Receptor-Positive Allosteric Modulator Reduces Neuropathic Pain in the Mouse with No Psychoactive Effects. Neuropsychopharmacology: Official Publication of the American College of Neuropsychopharmacology, 40(13), doi:10.1038/npp.2015.148. https://doi.org/10.1038/npp.2015.148

Islam, S. K., Cheng, Y. P., Birke, R. L., Green, O., Kubic, T., \& Lombardi, J. R. (2018). Rapid and sensitive detection of synthetic cannabinoids AMB-FUBINACA and $\alpha$-PVP using surface enhanced Raman scattering (SERS). Chemical Physics, 506, 31-35. https://doi.org/10.1016/j.chemphys.2018.03.028

Jacob, W., Yassouridis, A., Marsicano, G., Monory, K., Lutz, B., \& Wotjak, C. T. (2009). Endocannabinoids render exploratory behaviour largely independent of the test aversiveness: Role of glutamatergic transmission. Genes, Brain and Behavior, 8(7), 685- 
698. https://doi.org/10.1111/j.1601-183X.2009.00512.x

Jarbe, T. U., \& Raghav, J. G. (2016). Tripping with Synthetic Cannabinoids (“Spice”): Anecdotal and Experimental Observations in Animals and Man. In Neuropharmacology of New Psychoactive Substances (NPS) (Vol. 32, pp. 263-281). https://doi.org/10.1007/7854

Kenakin, T. (2013). Analytical pharmacology and allosterism: The importance of quantifying drug parameters in drug discovery. Drug Discovery Today: Technologies, 10(2), e229e235. https://doi.org/10.1016/j.ddtec.2012.07.006

Kevin, R. C., Wood, K. E., Stuart, J., Mitchell, A. J., Moir, M., Banister, S. D., ... McGregor, I. S. (2017). Acute and residual effects in adolescent rats resulting from exposure to the novel synthetic cannabinoids AB-PINACA and AB-FUBINACA. Journal of Psychopharmacology, 31(6), 757-769. https://doi.org/10.1177/0269881116684336

Kinsey, S. G., Bailey, M. T., Sheridan, J. F., Padgett, D. A., \& Avitsur, R. (2007). Repeated Social Defeat Causes Increased Anxiety-Like Behavior and Alters Splenocyte Function in C57BL/6 and CD-1 Mice. Brain Behavior and Immunology, 21(4), 458-466. https://doi.org/10.1038/nmeth.2250.Digestion

Kinsey, S. G., \& Cole, E. C. (2013). Acute $\Delta 9$-tetrahydrocannabinol blocks gastric hemorrhages induced by the nonsteroidal anti-inflammatory drug diclofenac sodium in mice. European Journal of Pharmacology, 715(1-3), 111-116. https://doi.org/10.1016/j.ejphar.2013.06.001

Kinsey, S. G., O’Neal, S. T., Long, J. Z., Cravatt, B. F., \& Lichtman, A. H. (2011). Inhibition of endocannabinoid catabolic enzymes elicits anxiolytic-like effects in the marble burying assay. Pharmacology Biochemistry and Behavior, 98(1), 21-27. https://doi.org/10.1016/j.pbb.2010.12.002

Lefever, T. W., Marusich, J. A., Thomas, B. F., Barrus, D. G., Peiper, N. C., Kevin, R. C., \& Wiley, J. L. (2017). Vaping synthetic cannabinoids: A novel preclinical model of Ecigarette use in mice. Substance Abuse: Research and Treatment, 11. https://doi.org/10.1177/1178221817701739

Levin, F. R., Mariani, J. J., Pavlicova, M., Brooks, D., Glass, A., Mahony, A., ... Choi, J. C. (2016). Dronabinol and lofexidine for cannabis use disorder : A randomized , 159, 53-60. https://doi.org/10.1016/j.drugalcdep.2015.11.025.

Lichtman, A H, Fisher, J., \& Martin, B. R. (2001). Precipitated cannabinoid withdrawal is reversed by Delta(9)-tetrahydrocannabinol or clonidine. Pharmacology, Biochemistry, and Behavior, 69(1-2), 181-188. https://doi.org/S0091-3057(01)00514-7 [pii]

Lichtman, Aron H, Fisher, J., \& Martin, B. R. (2001). Precipitated cannabinoid withdrawal is reversed by D 9 -tetrahydrocannabinol or clonidine, 69, 181-188.

Lombard, C., Nagarkatti, M., \& Nagarkatti, P. (2007). CB2 cannabinoid receptor agonist, JWH015, triggers apoptosis in immune cells: Potential role for CB2-selective ligands as immunosuppressive agents. Clinical Immunology, 122(3), 259-270. https://doi.org/10.1016/j.clim.2006.11.002

Long, J. Z., Li, W., Booker, L., Burston, J. J., Kinsey, S. G., Schlosburg, J. E., .. Cravatt, B. F. (2009). Selective blockade of 2-arachidonoylglycerol hydrolysis produces cannabinoid 
behavioral effects. Nature Chemical Biology, 5(1), 37-44.

https://doi.org/10.1038/nchembio.129

Lu, H. C., \& MacKie, K. (2016). An introduction to the endogenous cannabinoid system. Biological Psychiatry, 79(7), 516-525. https://doi.org/10.1016/j.biopsych.2015.07.028

Mackie, K. (2008). Cannabinoid Receptors : Where They are and What They do Neuroendocrinology, 20(11), 10-14. https://doi.org/10.1111/j.1365-2826.2008.01671.x

Marshell, R., Kearney-Ramos, T., Brents, L. K., Hyatt, W. S., Tai, S., Prather, P. L., \& Fantegrossi, W. E. (2014). In vivo effects of synthetic cannabinoids JWH-018 and JWH073 and phytocannabinoid $\triangle 9$-THC in mice: Inhalation versus intraperitoneal injection. Pharmacology Biochemistry and Behavior, 124, 40-47. https://doi.org/10.1016/j.pbb.2014.05.010

Mason, B. L., Mustafa, A., Filbey, F., Brown, E. S., \& Mason, B. L. (2016). Novel Pharmacotherapeutic Interventions for Cannabis Use Disorder. Current Addiction Reports. https://doi.org/10.1007/s40429-016-0094-y

Matsuda, L. a, Lolait, S. J., Brownstein, M. J., Young, A. C., \& Bonner, T. I. (1990). Structure of a cannabinoid receptor and functional expression of the cloned cDNA. Letters to Nature, $346,561-564$.

McKinney, M. K., \& Cravatt, B. F. (2005). Structure and Function of Fatty Acid Amide Hydrolase. Http://Dx.Doi.Org/10.1146/Annurev.Biochem.74.082803.133450. https://doi.org/10.1146/annurev.biochem.74.082803.133450

Mechoulam, R., Ben-Shabat, S., Hanus, L., Ligumsky, M., Kaminski, N., Schatz, A., ... Vogel, Z. (1995). Identification of an endogenous 2-monoglyceride, present in canine gut, that binds to cannabinoid receptors. Biochemical Pharmacology, 50(1), 83-90.

Mechoulam, R., \& Parker, L. a. (2012). The Endocannabinoid System and the Brain. Annual Review of Psychology, 64(1), 120717165617008. https://doi.org/10.1146/annurev-psych113011-143739

Meijer, K. A., Russo, R. R., \& Adhvaryu, D. V. (2014). Smoking Synthetic Marijuana Leads to Self-Mutilation Requiring Bilateral Amputations. Orthopedics, 37(4), e391-e394. https://doi.org/10.3928/01477447-20140401-62

Mir, A., Obafemi, A., Young, A., \& Kane, C. (2011). Myocardial Infarction Associated With Use of the Synthetic Cannabinoid K2. Pediatrics, 128(6), e1622-e1627. https://doi.org/10.1542/peds.2010-3823

Monte, A. A., Calello, D. P., Gerona, R. R., Hamad, E., Campleman, S. L., Brent, J., ... Carlson, R. G. (2017). Characteristics and Treatment of Patients with Clinical Illness Due to Synthetic Cannabinoid Inhalation Reported by Medical Toxicologists: A ToxIC Database Study. Journal of Medical Toxicology, 13(2), 146-152. https://doi.org/10.1007/s13181-0170605-9

Morean, M. E., Kong, G., Camenga, D. R., Cavallo, D. A., \& Krishnan-Sarin, S. (2015). High School Students' Use of Electronic Cigarettes to Vaporize Cannabis. Pediatrics, 136(4), 611-616. https://doi.org/10.1542/peds.2015-1727 
Moreira, F. A., Grieb, M., \& Lutz, B. (2009). Central side-effects of therapies based on CB1cannabinoid receptor agonists and antagonists: focus on anxiety and depression. Best Practice and Research: Clinical Endocrinology and Metabolism, 23(1), 133-144. https://doi.org/10.1016/j.beem.2008.09.003

Morgan, C. J. a, Schafer, G., Freeman, T. P., \& Curran, H. V. (2010). Impact of cannabidiol on the acute memory and psychotomimetic effects of smoked cannabis: Naturalistic study. British Journal of Psychiatry, 197(4), 285-290. https://doi.org/10.1192/bjp.bp.110.077503

Mu, J., Zhuang, S., Kirby, M. T., Hampson, R. E., \& Deadwyler, S. A. M. A. (1999). Cannabinoid Receptors Differentially Modulate Potassium A and D Currents in Hippocampal Neurons in Culture 1, 291(2), 893-902.

Muehlethaler, C., Leona, M., \& Lombardi, J. R. (2016). Review of Surface Enhanced Raman Scattering Applications in Forensic Science. Analytical Chemistry, 88(1), 152-169. https://doi.org/10.1021/acs.analchem.5b04131

Musshoff, F., Madea, B., Kern-Wighton, G., Bicker, W., Kneisel, S., Hutter, M., \& Auwarter, V. (2014). Driving under the influence of synthetic phenethylamines: a case series. International Journal of Legal Medicine, 128, 59-64. https://doi.org/10.1007/s00414-0151150-1

Nacca, N., Vatti, D., Sullivan, R., Sud, P., Su, M., \& Marraffa, J. (2013). The Synthetic Cannabinoid Withdrawal Syndrome. Journal of Addiction Medicine, 7(4), 296-298. https://doi.org/10.1177/0192513X12437708

Olea-Herrero, N., Vara, D., Malagarie-Cazenave, S., \& Díaz-Laviada, I. (2009). Inhibition of human tumour prostate PC-3 cell growth by cannabinoids R()-Methanandamide and JWH015: Involvement of CB 2. British Journal of Cancer, 101(6), 940-950. https://doi.org/10.1038/sj.bjc.6605248

Oliva, J. M., Servicio, S. O., Palomo, T., \& Manzanares, J. (2004). Spontaneous cannabinoid withdrawal produces a differential time-related responsiveness in cannabinoid CB1 receptor gene expression in the mouse brain José. Journal of Psychopharmacology, 18(1), 59-65. https://doi.org/10.1177/0192513X12437708

Papanti, D., Schifano, F., Botteon, G., Bertossi, F., Mannix, J., Vidoni, D., ... Bonavigo, T. (2013). "Spiceophrenia": a systematic overview of "Spice"-related psychopathological issues and a case report Duccio. Human Psychopharmacology Clin Exp, 28(3), 379-389. https://doi.org/10.1002/hup

Paronis, C. A., Nikas, S. P., Shukla, V. G., \& Makriyannis, A. (2012). 9-Tetrahydrocannabinol acts as a partial agonist/antagonist in mice. Behavioural Pharmacology, 23(8), 802-805. https://doi.org/10.1097/FBP.0b013e32835a7c4d

Patel, S., Roelke, C. T., Rademacher, D. J., \& Hillard, C. J. (2005). Inhibition of restraint stressinduced neural and behavioural activation by endogenous cannabinoid signalling. European Journal of Neuroscience, 21(4), 1057-1069. https://doi.org/10.1111/j.14609568.2005.03916.x

Patton, A. L., Chimalakonda, K. C., Moran, C. L., Mccain, K. R., Radominska-Pandya, A., 
James, L. P., ... Moran, J. H. (2013). K2 Toxicity: Fatal case of psychiatric complications following AM2201 exposure. Journal of Forensic Sciences, 58(6), 1676-1680.

https://doi.org/10.1111/1556-4029.12216

Pertwee, R. G. (2009). Emerging strategies for exploiting cannabinoid receptor agonists as medicines. British Journal of Pharmacology, 156(3), 397-411.

https://doi.org/10.1111/j.1476-5381.2008.00048.x

Qamri, Z., Preet, A., Nasser, M. W., Bass, C. E., Leone, G., Barsky, S. H., \& Ganju, R. K. (2009). Synthetic cannabinoid receptor agonists inhibit tumor growth and metastasis of breast cancer. Molecular Cancer Therapeutics, 8(11), 3117-3129. https://doi.org/10.1158/1535-7163.MCT-09-0448

Ramesh, D., \& Haney, M. (2015). Textbook of Addiction Treatment: International Perspectives. Textbook of Addiction Treatment: International Perspectives, 367-380. https://doi.org/10.1007/978-88-470-5322-9

Ross, R. A. (2007). Allosterism and cannabinoid CB1receptors: the shape of things to come. Trends in Pharmacological Sciences, 28(11), 567-572. https://doi.org/10.1016/j.tips.2007.10.006

Sampson, C. S., Bedy, S., \& Carlisle, T. (2015). Withdrawal Seizures Seen In the Setting of Synthetic Cannabinoid Abuse. American Journal of Emergency Medicine, 33. https://doi.org/10.1016/j.ajem.2015.03.025

Schaefer, N., Peters, B., Bregel, D., Kneisel, S., Schmidt, P. H., \& Ewald, A. H. (2013). A fatal case involving several synthetic cannabinoids. Toxichem Krimtech, 80(January), 248-251.

Schlosburg, J. E., Blankman, J. L., Long, J. Z., Nomura, D. K., Pan, B., Kinsey, S. G., ... Cravatt, B. F. (2010). Chronic monoacylglycerol lipase blockade causes functional antagonism of the endocannabinoid system. Nature Neuroscience, 13(9), 1113-1119. https://doi.org/10.1038/nn.2616

Schlosburg, J. E., Carlson, B. L. a, Ramesh, D., Abdullah, R. a, Long, J. Z., Cravatt, B. F., \& Lichtman, A. H. (2009). Inhibitors of endocannabinoid-metabolizing enzymes reduce precipitated withdrawal responses in THC-dependent mice. The AAPS Journal, 11(2), 342352. https://doi.org/10.1208/s12248-009-9110-7

Schreiber, S., Bader, M., Lenchinski, T., Meningher, I., Rubovitch, V., Katz, Y., ... Pick, C. G. (2018). Functional effects of synthetic cannabinoids versus $\Delta 9$-THC in mice on body temperature, nociceptive threshold, anxiety, cognition, locomotor/exploratory parameters and depression. Addiction Biology. https://doi.org/10.1111/adb.12606

Seely, K. A., Lapoint, J., Moran, J. H., \& Fattore, L. (2012). Spice drugs are more than harmless herbal blends: A review of the pharmacology and toxicology of synthetic cannabinoids. Progress in Neuro-Psychopharmacology and Biological Psychiatry, 39(2), 234-243. https://doi.org/10.1016/j.pnpbp.2012.04.017

Singh, U. P., Singh, N. P., Singh, B., Price, R. L., Nagarkatti, M., \& Nagarkatti, P. S. (2012). Cannabinoid receptor-2 (CB2) agonist ameliorates colitis in IL-10 -/- mice by attenuating the activation of T cells and promoting their apoptosis. Toxicology and Applied 
Pharmacology, 258(2), 256-267. https://doi.org/10.1016/j.taap.2011.11.005

Slivicki, R. A., Xu, Z., Kulkarni, P. M., Pertwee, R. G., Mackie, K., Thakur, G. A., \& Hohmann, A. G. (2017). Positive Allosteric Modulation of Cannabinoid Receptor Type 1 Suppresses Pathological Pain Without Producing Tolerance or Dependence. Biological Psychiatry, 011(26), 1-12. https://doi.org/10.1016/j.biopsych.2017.06.032

Sobolevsky, T., Prasolov, I., \& Rodchenkov, G. (2010). Detection of JWH-018 metabolites in smoking mixture post-administration urine. Forensic Science International, 200(1-3), 141147. https://doi.org/10.1016/j.forsciint.2010.04.003

Steiner, M. A., \& Wotjak, C. T. (2008). Role of the endocannabinoid system in regulation of the hypothalamic-pituitary-adrenocortical axis. Progress in Brain Research, 170(08), 397-432. https://doi.org/10.1016/S0079-6123(08)00433-0

Steru, L., Chermat, R., Thierry, B., \& Siman, P. (1985). The tail suspension test: A new method for screening antidepressant in mice. Psychopharmacology, 85(September), 367.

Su, M. K., Seely, K. A., Moran, J. H., \& Hoffman, R. S. (2015). Metabolism of Classical Cannabinoids and the Synthetic Cannabinoid JWH-018. Clinical Pharmacology and Therapeutics, 97(6), 562-564. https://doi.org/10.1002/cpt.114

Substance Use and Mental Health Services Administration. (2015). Results from the 2015 National Survey on Drug Use and Health: Detailed Tables,. 2015 National Survey on Drug Use and Health. Retrieved from https://www.samhsa.gov/data/sites/default/files/NSDUHDetTabs-2015/NSDUH-DetTabs-2015/NSDUH-DetTabs-2015.htm\#tab5-1c

Thomas, G., Kloner, R. A., \& Rezkalla, S. (2014). Adverse cardiovascular, cerebrovascular, and peripheral vascular effects of marijuana inhalation: What cardiologists need to know. American Journal of Cardiology, 113(1), 187-190. https://doi.org/10.1016/j.amjcard.2013.09.042

Trecki, J., Gerona, R. R., \& Schwartz, M. D. (2015). Synthetic Cannabinoid-Related Illnesses and Deaths. New England Journal of Medicine, 373(2), 103-107. https://doi.org/10.1056/NEJMp1504912

Trexler, K R, Eckard, M. L., \& Kinsey, S. G. (2019). CB1 positive allosteric modulation attenuates $\triangle 9$-THC withdrawal and NSAID-induced gastric inflammatio. Pharmacology, Biochemistry and Behavior, 177(December 2018), 27-33. https://doi.org/10.1016/j.pbb.2018.12.009

Trexler, Kristen R., Nass, S. R., Crowe, M. S., Gross, J. D., Jones, M. S., McKitrick, A. W., ... Kinsey, S. G. (2018). Novel behavioral assays of spontaneous and precipitated THC withdrawal in mice. Drug and Alcohol Dependence. https://doi.org/10.1016/j.drugalcdep.2018.05.029

Vallersnes, O. M., Dines, A. M., Wood, D. M., Yates, C., Heyerdahl, F., Hovda, K. E., ... Dargan, P. I. (2016). Psychosis associated with acute recreational drug toxicity: A European case series. BMC Psychiatry, 16(293). https://doi.org/10.1186/s12888-016-1002-7

van Amsterdam, J., Brunt, T., \& van den Brink, W. (2015). The adverse health effects of synthetic cannabinoids with emphasis on psychosis-like effects. Journal of 
Psychopharmacology, 29(3), 254-263. https://doi.org/10.1177/0269881114565142

Wiebelhaus, J. M., Poklis, J. L., Poklis, A., Vann, R. E., Lichtman, A. H., \& Wise, L. E. (2012). Inhalation exposure to smoke from synthetic "marijuana" produces potent cannabimimetic effects in mice. Drug and Alcohol Dependence, 126(3), 316-323. https://doi.org/10.1016/j.drugalcdep.2012.05.034

Wiley, J. L., Marusich, J. A., Lefever, T. W., Antonazzo, K. R., Wallgren, M. T., Cortes, R. A., ... Thomas, B. F. (2015). AB-CHMINACA, AB-PINACA, and FUBIMINA: Affinity and Potency of Novel Synthetic Cannabinoids in Producing 9-Tetrahydrocannabinol-Like Effects in Mice. Journal of Pharmacology and Experimental Therapeutics, 354(3), 328339. https://doi.org/10.1124/jpet.115.225326 

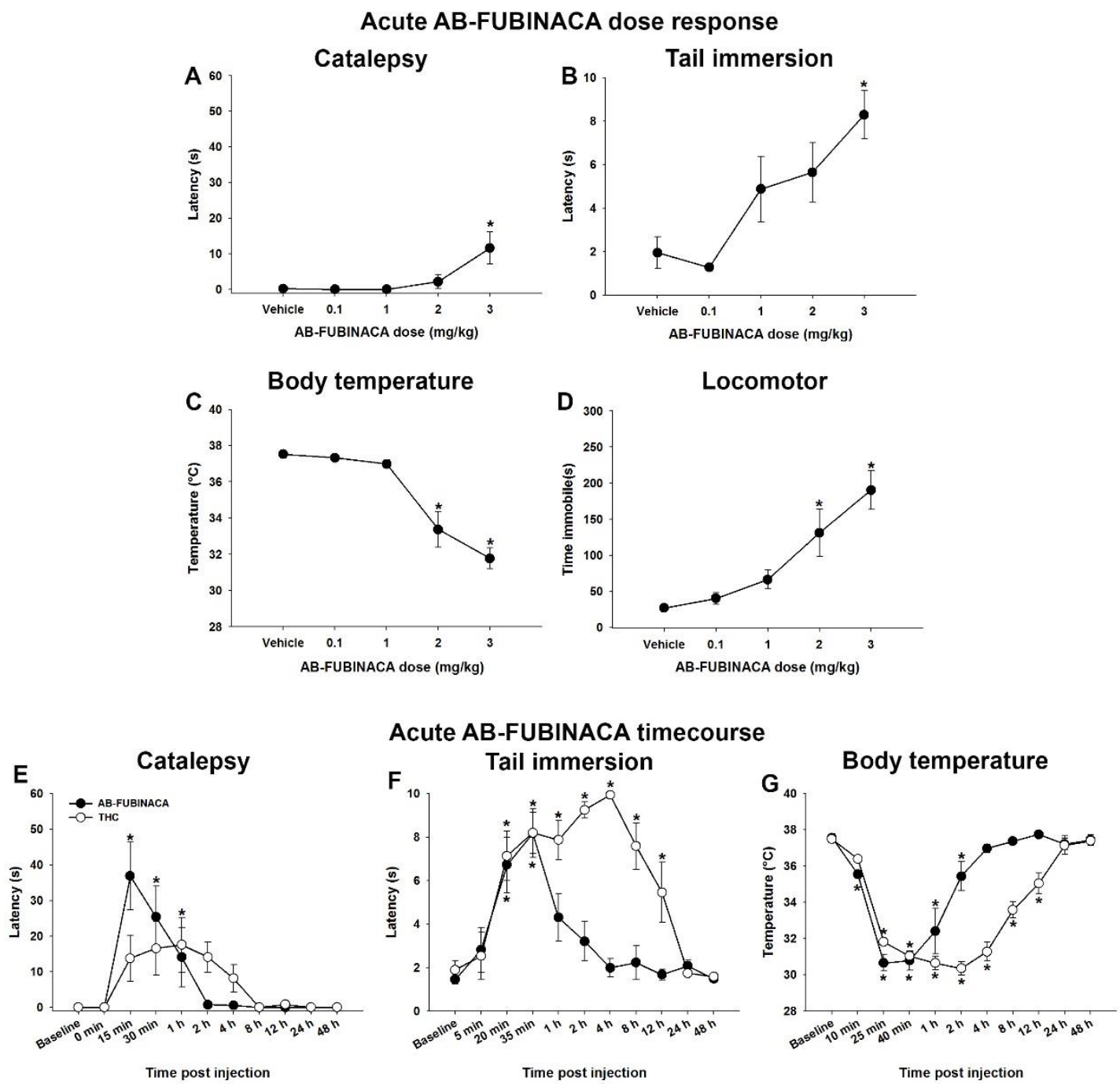

Figure 3. AB-FUBINACA has short-acting cannabinoid effects. Male and female mice were treated with AB-FUBINACA (0.1-3 mg/kg, i.p.) 30 min prior to testing in the tetrad battery. ABFUBINACA induced catalepsy (A) antinociception (B), hypothermia (C), and hypolocomotion (D), consistent with established cannabinoid effects. A second group of male and female mice was injected with AB-FUBINACA (3 mg/kg, i.p.) or THC $(50 \mathrm{mg} / \mathrm{kg})$ and tested repeatedly in a modified tetrad battery. The effects of AB-FUBINACA abated more quickly than the effects of THC in catalepsy $(\mathbf{E})$, antinociception $(\mathbf{F})$, and hypothermia $(\mathbf{G})$. Data represent mean $\pm \mathrm{SEM}$ ( $\mathrm{n}=8[4 \mathrm{~m} / 4 \mathrm{f}] /$ group $) ; \mathrm{*}<.05 \mathrm{v}$. vehicle or baseline. 


\section{AB-FUBINACA (3 mg/kg) tolerance}
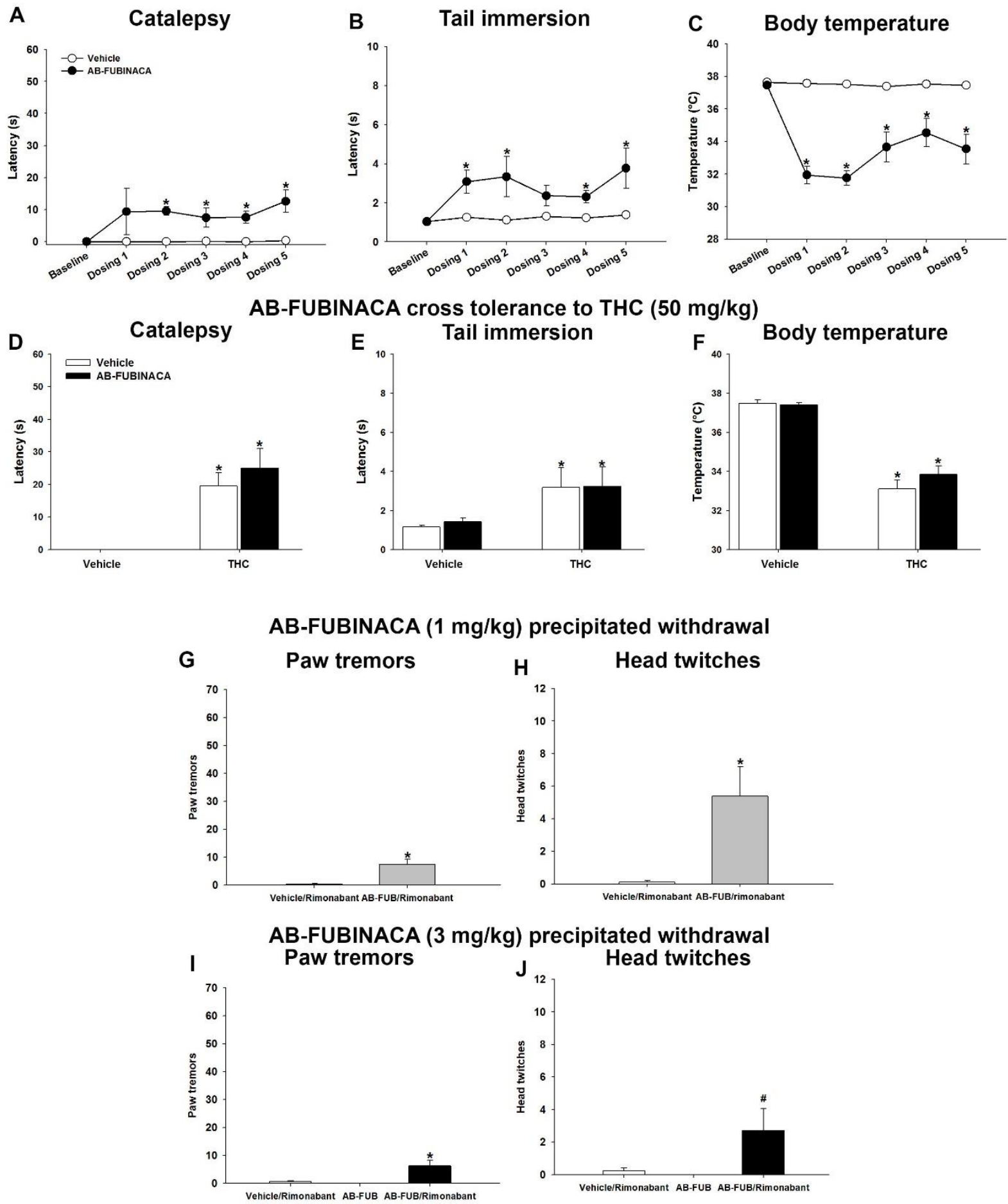

Figure 4. Chronic effects of AB-FUBINACA. Mice were treated with twice daily with ABFUBINACA ( $3 \mathrm{mg} / \mathrm{kg}$, i.p.) or vehicle for 5 days. Mice were assessed in a modified tetrad battery every morning approximately $30 \mathrm{~min}$ after injections. Mice treated with AB-FUBINACA did not develop tolerance to its effects in catalepsy (A), tail immersion (B), or body temperature 
(C). On the $6^{\text {th }}$ day, mice were baselined, then injected with THC $(50 \mathrm{mg} / \mathrm{k}$, i.p.) to evaluate cross-tolerance. Mice treated with AB-FUBINACA showed no cross tolerance to THC in catalepsy (D), antinociception (E), or hypothermia (F). To evaluate precipitated withdrawal from AB-FUBINACA, separate groups of mice were treated with AB-FUBINACA (1 or $3 \mathrm{mg} / \mathrm{kg}$, i.p.) twice daily for 6 days. On the $6^{\text {th }}$ day, mice were injected with rimonabant and then evaluated for somatic signs of withdrawal. AB-FUBINACA ( 1 or $3 \mathrm{mg} / \mathrm{kg}$ ) increased paw tremors $(\mathbf{G} \& \mathbf{I})$ and head twitches $(\mathbf{H} \& \mathbf{J})$. Data represent mean \pm SEM (n=8-10 [4-5m/4-5f] /group); * $\mathrm{p}<.05 \mathrm{v}$. vehicle or baseline; $\# \mathrm{p}<.05 \mathrm{v}$. AB-FUB/vehicle. 

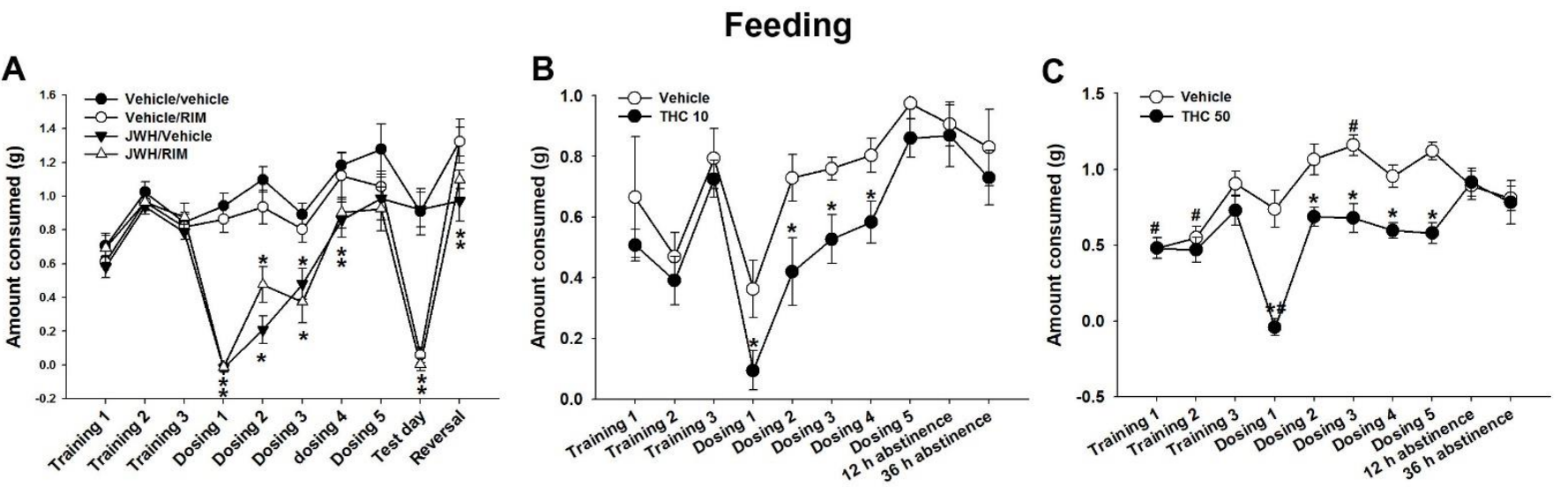

Figure 5. Spontaneous THC withdrawal had no effect on feeding. Mice were treated twice daily with JWH-018 (1 mg/kg) or vehicle for 6 days and were then subjected to precipitated withdrawal. Rimonabant decreased drinking in both JWH-018 and vehicle treated mice (A). Mice were treated with twice daily with THC $(10 \mathrm{mg} / \mathrm{kg}$, i.p. $)$ or vehicle for 5 days. Mice were assessed an anhedonia assay $12 \mathrm{~h}$ and $36 \mathrm{~h}$ after the final THC or vehicle injection (B). No effect of spontaneous THC $(10 \mathrm{mg} / \mathrm{kg})$ withdrawal was observed. Similarly, mice treated for 5 days with THC (50 mg/kg, i.p.) or vehicle did not show spontaneous withdrawal at $12 \mathrm{~h}$ or $36 \mathrm{~h}$ (C). Data represent mean \pm SEM ( $=8$ [4m/4f]/group) * $\mathrm{p}<.05$ v. vehicle control; \#p<.05 v. own baseline (Training 3). 

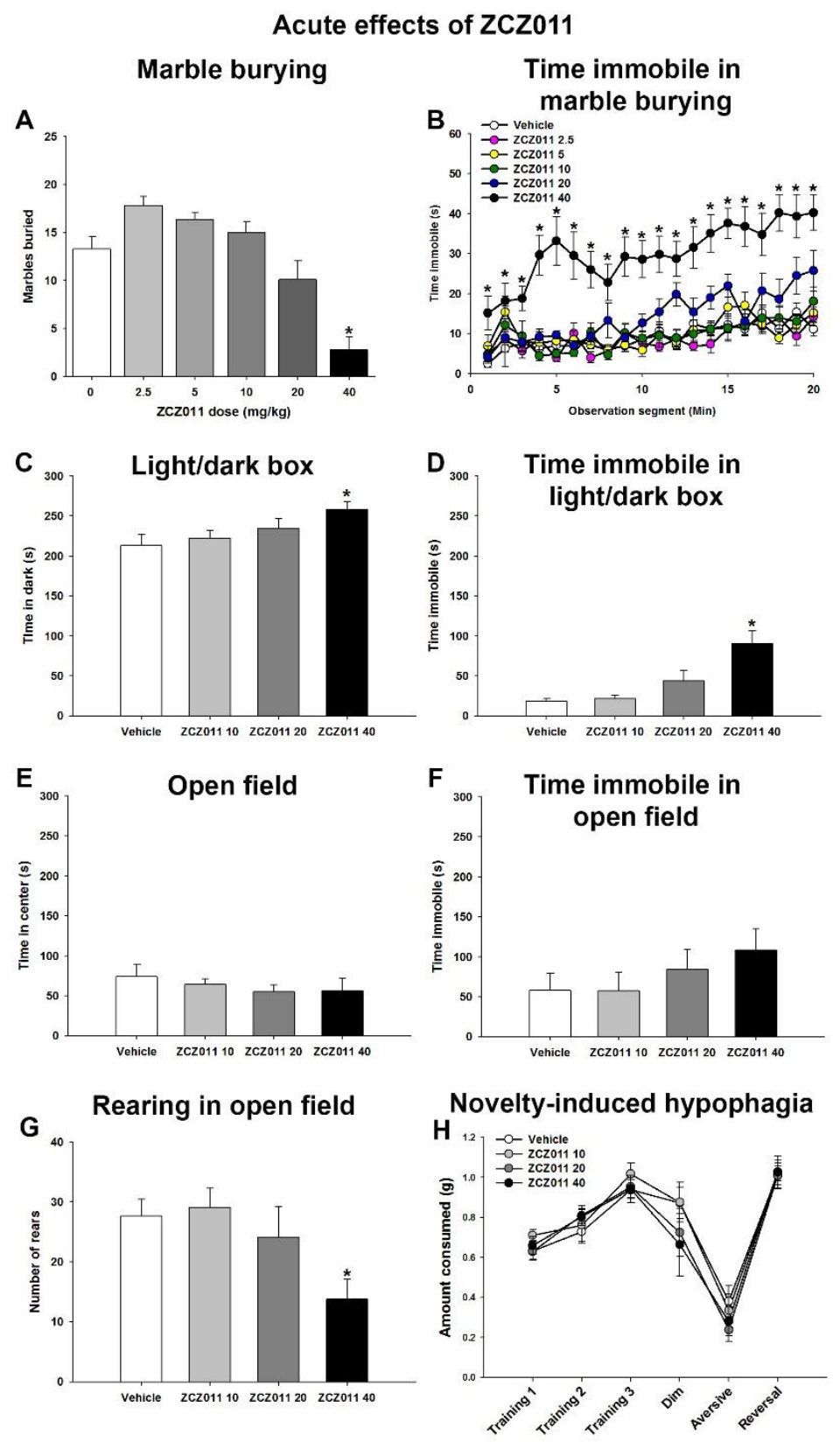

Figure 6. Acute ZCZ011 decreased marble burying and increased immobility in a subset of tests. Separate groups of mice were treated with acute ZCZ011 (2.5-40 mg/kg, i.p.) or vehicle $75 \mathrm{~min}$ prior to testing. Mice treated with ZCZ011 (40 mg/kg) buried fewer marbles (A) and spent more time immobile in marble burying (B). Mice treated with ZCZ011 (40 mg/kg) spent more time in the dark (C) and more time immobile in the light/dark box test (D). Mice treated with ZCZ011 $(40 \mathrm{mg} / \mathrm{kg})$ did not differ in time spent in the center of the open field (E) or time spent immobile (F) but reared less (G). ZCZ011 did not affect amount consumed in novelty-induced hypophagia

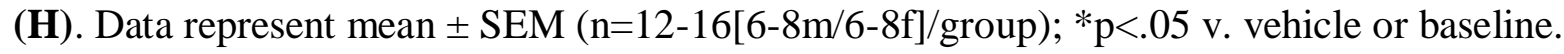




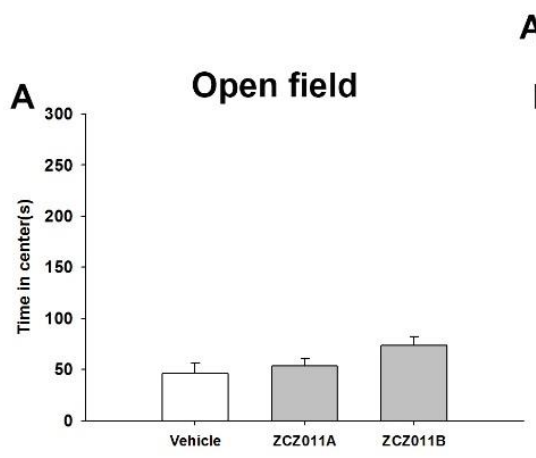

Acute effects of ZCZ011 enantiomers
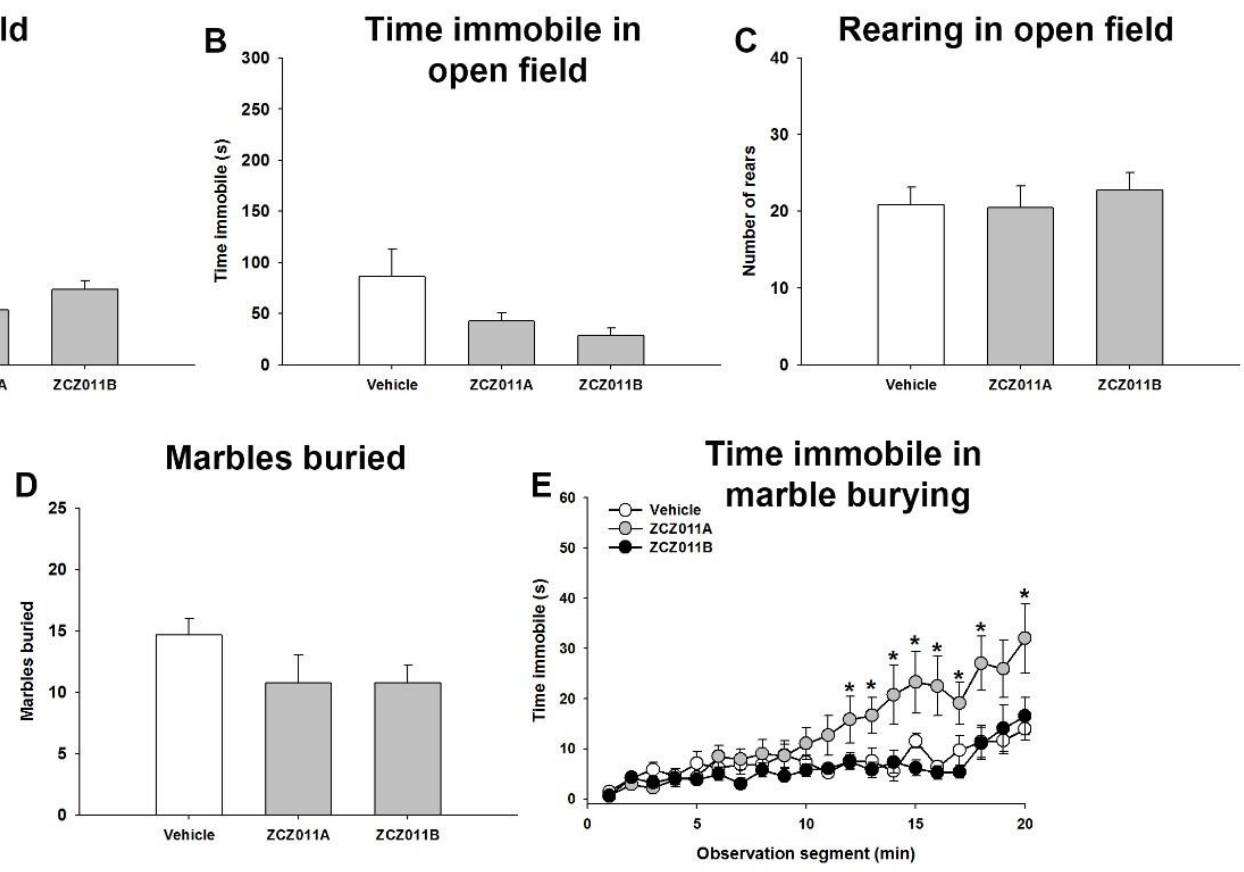

Figure 7. Acute effects of ZCZ011 enantiomers. Mice were treated with either acute ZCZ011A (20 mg/kg, i.p.), ZCZ011B (20 mg/kg, i.p.) or vehicle $75 \mathrm{~min}$ prior to testing .Neither ZCZ011A nor ZCZ011B affected time in the center of the open field (A), time immobile during open field (B), or rearing (C). Neither ZCZ011A nor ZCZ011B affected marbled buried (D), but ZCZ011A increased time spent immobile in marble burying $(\mathbf{E})$. Data represent mean \pm SEM $(\mathrm{n}=12[6 \mathrm{~m} / 6 \mathrm{f}] /$ group$) ;{ }^{*} \mathrm{p}<.05 \mathrm{v}$. vehicle or baseline. 
THC (10 $\mathrm{mg} / \mathrm{kg}$ ) withdrawal challenged by ZCZ011
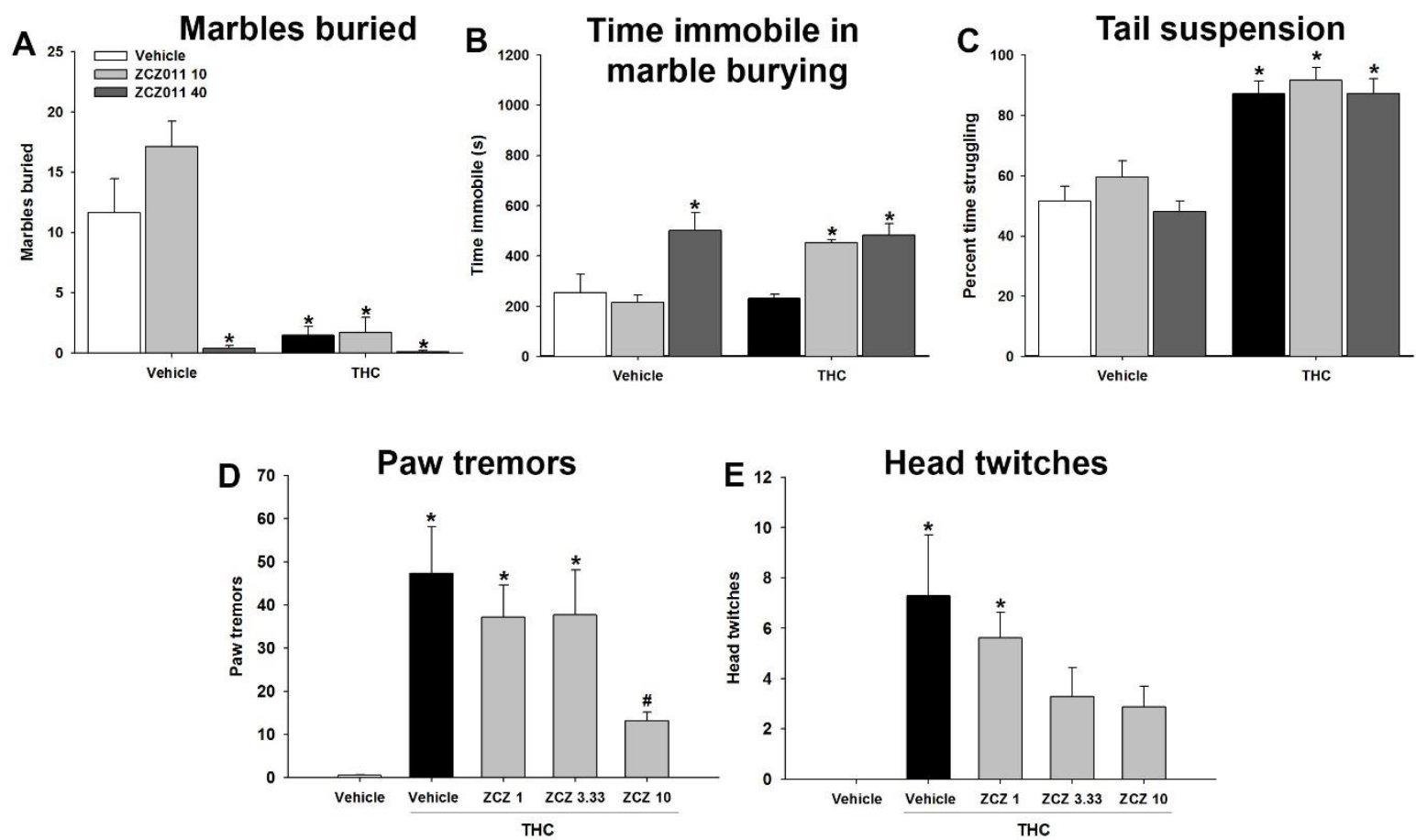

THC (10 mg/kg) withdrawal challenged by ZCZ011 enantiomers
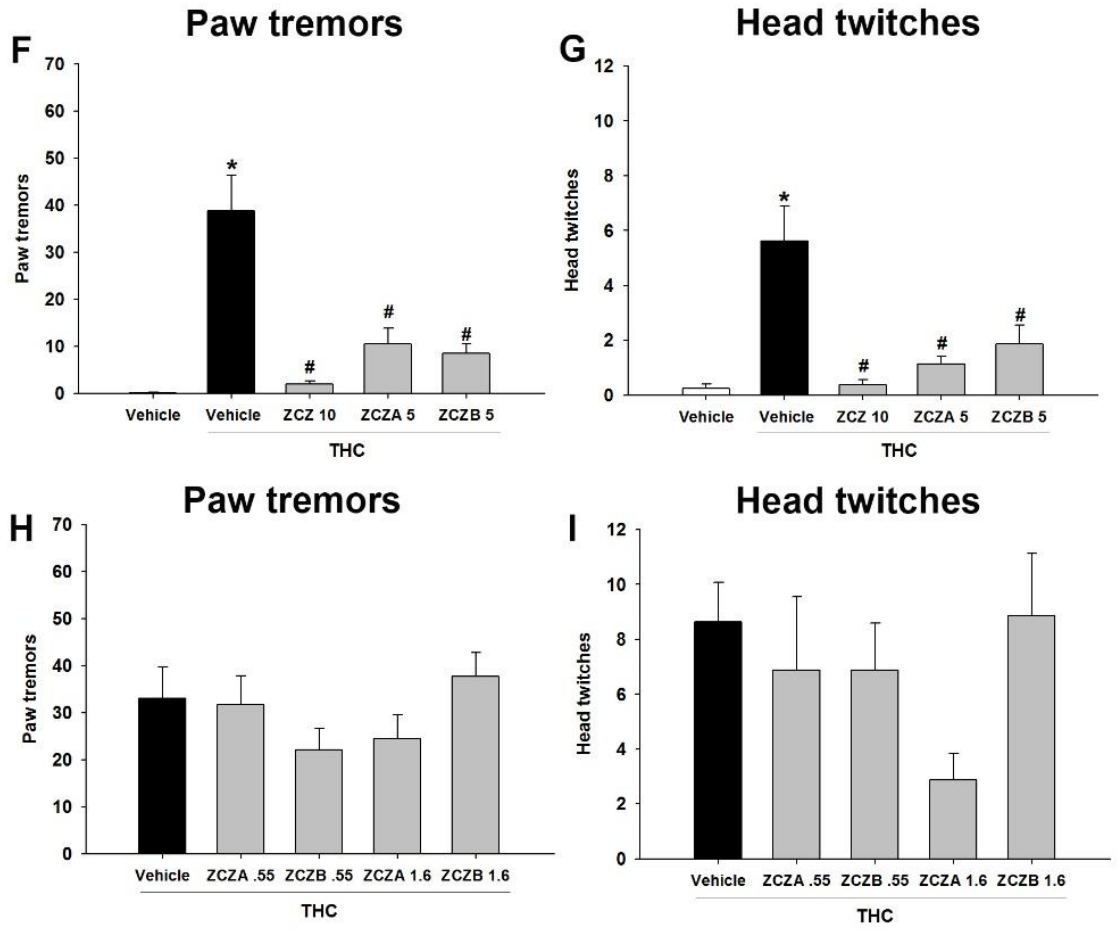

Figure 8. ZCZ011 attenuates somatic signs of precipitated THC withdrawal. Separate groups of mice were treated with THC $(10 \mathrm{mg} / \mathrm{kg}$, i.p. $)$ or vehicle twice daily for 6 days. On the $6^{\text {th }}$ day, 
mice were injected with ZCZ011 (1-40 mg/kg) or vehicle, then injected with rimonabant and then evaluated in marble burying and tail suspension or somatic signs of withdrawal. ZCZ011 (10 or $40 \mathrm{mg} / \mathrm{kg}$ ) did not attenuate withdrawal-induced changes in marble burying (A) or tail suspension test (C). ZCZ011 (10 or $40 \mathrm{mg} / \mathrm{kg}$ increased immobility in mice subjected to withdrawal in marble burying (B). ZCZ011 (10 mg/kg) attenuated paw tremors (D) and head twitches (E). In a second set of experiments, mice were treated on the $6^{\text {th }}$ day with ZCZ011A (0.55-5 mg/kg, i.p.), ZCZ011B (0.55-5 mg/kg, i.p.) or vehicle, then injected with rimonabant and evaluated for somatic signs of THC withdrawal. Both ZCZ011A (5 mg/kg) and ZCZ011B (5 $\mathrm{mg} / \mathrm{kg}$ ) attenuated paw tremors (F) and head twitches $(\mathbf{G})$. Neither ZCZ011 A (0.55 or 1.66 $\mathrm{mg} / \mathrm{kg})$ nor ZCZ011B $(0.55$ or $1.6 \mathrm{mg} / \mathrm{kg})$ attenuated paw tremors $(\mathbf{H})$ or head twitches (I). Data represent mean \pm SEM $(\mathrm{n}=8[4 \mathrm{~m} / 4 \mathrm{f}] /$ group $) ;{ }^{*} \mathrm{p}<.05 \mathrm{v}$. vehicle or baseline, $\# \mathrm{p}<.05 \mathrm{v}$. THC/Vehicle. 
Appendix A. Analysis of covariance (ANCOVA) for experiments 2, 3a, and 3b.

To standardize drinking across days in the anhedonia assays in experiment 2, an analysis of covariance (ANCOVA) was conducted using baseline as a covariate. Even when baseline consumption was considered, there was no difference in consumption between THC (10 mg/kg) and vehicle treated mice at $12 \mathrm{~h}[\mathrm{p}=.80]$ or $36 \mathrm{~h}[\mathrm{p}=.76]$. When baseline was used as a covariate for THC (50 mg/kg) withdrawal, again, at $12 \mathrm{~h}$ there was no difference in consumption [p=.07]. Interestingly, THC (50 mg/kg) withdrawal caused a significant decrease in consumption at $36 \mathrm{~h}$ when analyzed using ANCOVA $[\mathrm{F}(1,11)=9.07, \mathrm{p}<.05]$.

I speculated that the decrease in marbles buried and increase in time spent in the dark observed in experiment 3a following ZCZ011 administration was due to increased immobility. To determine whether immobility affected marbles buried and time spent in the dark during light/dark box, separate ANCOVAs were done using time immobile as the covariate. Indeed, when analyzed with ANCOVA, the initial decrease in marbles buried is no longer significant $[\mathrm{p}=.17]$, nor is the increase in time spent in the dark during the light/dark box test [p=.08]. This indicates that the observed changes were related to increased immobility.

Finally, in experiment 3b, I speculated that the decrease in marbles buried in ZCZ011 treated mice was due to increased immobility. Again, an ANCOVA was done to determine whether this was the case and again, the decrease in marbles buried was no longer significant when immobility was taken into account as a covariate $[\mathrm{p}=.86]$. 
Appendix B. Table of post hoc analyses. The post hoc analyses completed for the present experiments are listed in the table below. Bold indicates significance.

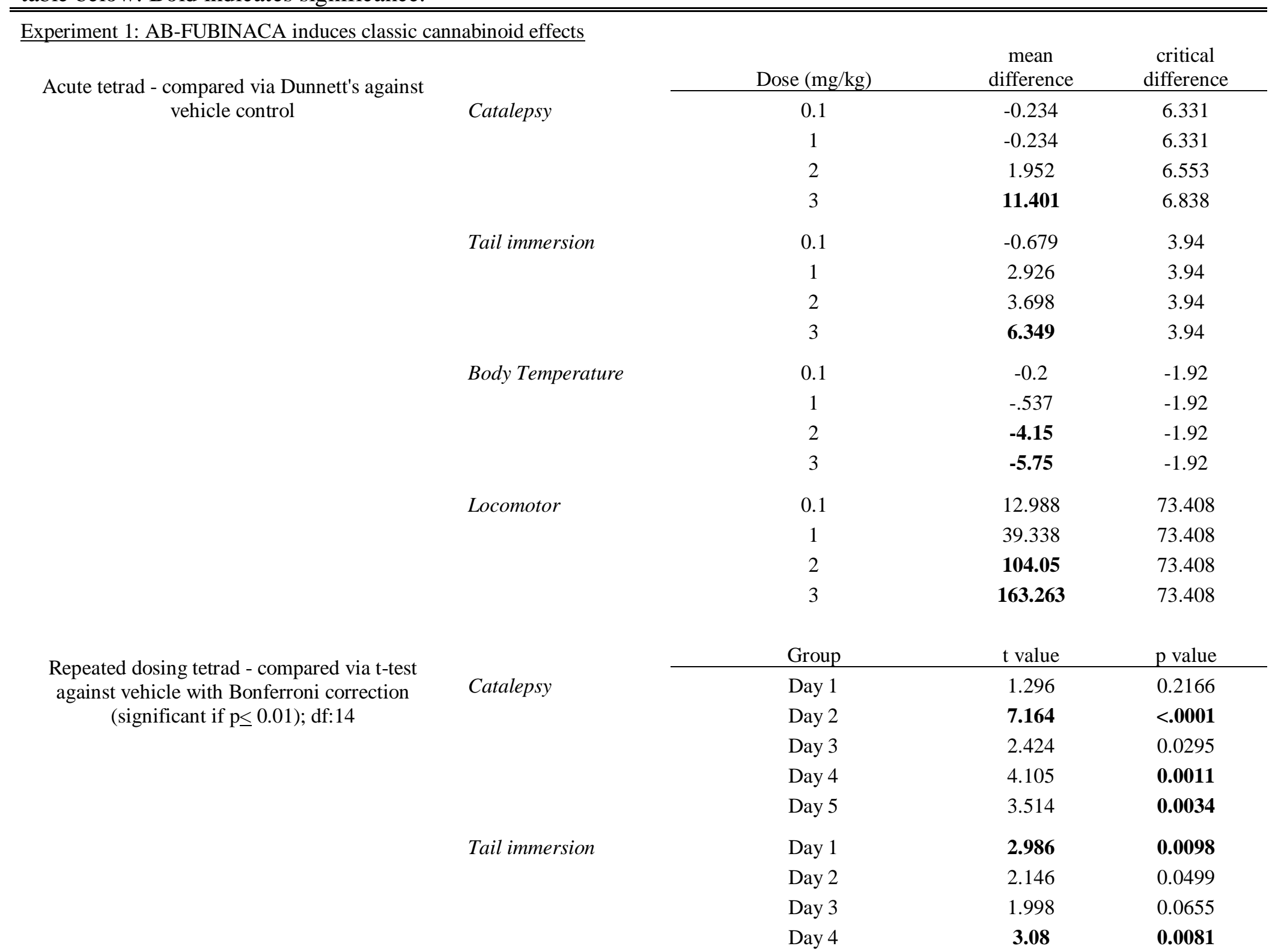


AB-FUBINACA $(3 \mathrm{mg} / \mathrm{kg})$ precipitated withdrawal - compared via Bonferroni (significant

$$
\text { if } \mathrm{p} \leq 0.0167)
$$

AB-FUBINACA and THC tetrad timecourse compared via Dunnett against baseline
Head twitches

Body Temperature

\author{
Paw tremors
}

Catalepsy

Catalepsy

Tail immersion

$\begin{array}{ccc}\text { Day 5 } & 2.292 & 0.0379 \\ \text { Day 1 } & \mathbf{- 1 0 . 4 1 3} & <.0001 \\ \text { Day 2 } & \mathbf{- 1 2 . 6} & <.0001 \\ \text { Day 3 } & \mathbf{- 3 . 9 8} & \mathbf{0 . 0 0 1 4} \\ \text { Day 4 } & \mathbf{- 3 . 2 9 7} & \mathbf{0 . 0 0 5 3} \\ \text { Day 5 } & \mathbf{- 4 . 2 7 6} & \mathbf{0 . 0 0 0 8}\end{array}$

\begin{tabular}{cccc} 
Comparison & $\begin{array}{c}\text { Mean } \\
\text { difference }\end{array}$ & $\begin{array}{c}\text { critical } \\
\text { difference }\end{array}$ & p value \\
\hline Vehicle v. AB-F & 0.625 & 3.839 & 0.6751 \\
Vehicle v. AB-F/Rim & $\mathbf{- 5 . 5 1 8}$ & 3.974 & $\mathbf{0 . 0 0 1 7}$ \\
AB-F v. AB-F/Rim & $\mathbf{- 6 . 1 4 3}$ & 3.974 & $\mathbf{0 . 0 0 0 6}$ \\
Vehicle v. AB-F & 0.25 & 2.652 & .8 .14 \\
Vehicle v. AB-F/Rim & -2.464 & 2.652 & 0.0248 \\
AB-F v. AB-F/Rim & $\mathbf{- 2 . 7 1 4}$ & 2.652 & $\mathbf{0 . 0 1 4 6}$
\end{tabular}

\begin{tabular}{ccccc} 
& \multicolumn{2}{c}{ AB-FUBINACA } & \multicolumn{2}{c}{ THC } \\
Timepoint & Mean & Critical & Mean & Critical \\
Difference & Difference & Difference & Difference \\
\hline 0 min & 0 & 18.715 & 0 & 15.823 \\
15 min & $\mathbf{3 6 . 8 8 1}$ & $\mathbf{1 8 . 7 1 5}$ & 13.755 & 15.823 \\
30 min & $\mathbf{2 5 . 3 2 7}$ & $\mathbf{1 8 . 7 1 5}$ & $\mathbf{1 6 . 5 8 5}$ & $\mathbf{1 5 . 8 2 3}$ \\
lh & 14.046 & 18.715 & $\mathbf{1 7 . 5 5 8}$ & $\mathbf{1 5 . 8 2 3}$ \\
$2 \mathrm{~h}$ & 0.748 & 18.715 & 14.134 & 15.823 \\
$4 \mathrm{~h}$ & 0.564 & 18.715 & 8.129 & 15.823 \\
$8 \mathrm{~h}$ & 0 & 18.715 & 0 & 15.823 \\
$12 \mathrm{~h}$ & 0 & 18.715 & 0.851 & 15.823 \\
$24 \mathrm{~h}$ & 0 & 18.715 & 0 & 15.823 \\
$48 \mathrm{~h}$ & 0 & 18.715 & 0 & 15.823 \\
5 min & 1.357 & 2.897 & 0.643 & 3.082 \\
20 min & $\mathbf{5 . 2 7 9}$ & $\mathbf{2 . 8 9 7}$ & $\mathbf{5 . 2 4 8}$ & $\mathbf{3 . 0 8 2}$ \\
35 min & $\mathbf{6 . 7 3 1}$ & $\mathbf{2 . 8 9 7}$ & $\mathbf{6 . 3 0 9}$ & $\mathbf{3 . 0 8 2}$
\end{tabular}




\begin{tabular}{|c|c|c|c|c|c|}
\hline & $1 \mathrm{~h}$ & 2.865 & 2.897 & 5.978 & 3.082 \\
\hline & $2 \mathrm{~h}$ & 1.769 & 2.897 & 7.365 & 3.082 \\
\hline & $4 \mathrm{~h}$ & 0.549 & 2.897 & 8.053 & 3.082 \\
\hline & $8 \mathrm{~h}$ & 0.786 & 2.897 & 5.698 & 3.082 \\
\hline & $12 \mathrm{~h}$ & 0.226 & 2.897 & 3.569 & 3.082 \\
\hline & $24 \mathrm{~h}$ & 0.63 & 2.897 & -0.153 & 3.082 \\
\hline & $48 \mathrm{~h}$ & 0.042 & 2.897 & -0.314 & 3.082 \\
\hline \multirow[t]{10}{*}{ Body Temperature } & $10 \mathrm{~min}$ & -2.013 & 1.751 & -1.088 & 1.185 \\
\hline & $25 \mathrm{~min}$ & -6.913 & 1.751 & -5.675 & 1.185 \\
\hline & $40 \mathrm{~min}$ & -6.775 & 1.751 & -6.45 & 1.185 \\
\hline & $1 \mathrm{~h}$ & -5.163 & 1.751 & -6.838 & 1.185 \\
\hline & $2 \mathrm{~h}$ & -2.125 & 1.751 & -7.137 & 1.185 \\
\hline & $4 \mathrm{~h}$ & -0.587 & 1.751 & -6.213 & 1.185 \\
\hline & $8 \mathrm{~h}$ & -0.188 & 1.751 & -3.913 & 1.185 \\
\hline & $12 \mathrm{~h}$ & 0.188 & 1.751 & -2.45 & 1.185 \\
\hline & $24 \mathrm{~h}$ & -0.35 & 1.751 & -0.35 & 1.185 \\
\hline & $48 \mathrm{~h}$ & -0.125 & 1.751 & -0.1 & 1.185 \\
\hline
\end{tabular}

Experiment 2: Spontaneous THC withdrawal does not affect feeding

JWH-018 spontaneous withdrawal - compared via

ANOVA with Bonferroni correction (significant if $\mathrm{p} \leq 0.005) ; \mathrm{df}: 1,28$

\begin{tabular}{ccc} 
Timepoint & f value & p value \\
\hline Training day 1 & 0.088 & 0.7685 \\
Training day 2 & 0.507 & 0.4822 \\
Training day 3 & 0 & 0.9994 \\
Dosing day 1 & $\mathbf{2 7 9 . 3 3 6}$ & $<.0001$ \\
Dosing day 2 & $\mathbf{5 2 . 7 3 2}$ & $<.0001$ \\
Dosing day 3 & $\mathbf{1 9 . 0 1 2}$ & $\mathbf{0 . 0 0 0 2}$ \\
Dosing day 4 & 7.002 & 0.0132 \\
Dosing day 5 & 2.69 & 0.1122 \\
Test day & 0.057 & 0.8137 \\
Reversal day & 8.114 & 0.0081 \\
& & \\
Training day 1 & 0.016 & 0.9004 \\
Training day 2 & 0.082 & 0.7766
\end{tabular}

Rimonabant main effects

JWH-018 main effects

Training day 2 
THC spontaneous withdrawal - compared via t test with Bonferroni correction (significant if $\mathrm{p} \leq 0.005) ; \mathrm{df}: 14$

\begin{tabular}{|c|c|c|c|}
\hline & Training day 3 & 0.195 & 0.6626 \\
\hline & Dosing day 1 & 0.463 & 0.5018 \\
\hline & Dosing day 2 & 0.31 & 0.5823 \\
\hline & Dosing day 3 & 1.023 & 0.3205 \\
\hline & Dosing day 4 & 0.01 & 0.9204 \\
\hline & Dosing day 5 & 1.189 & 0.2848 \\
\hline & Test day & 95.051 & $<.0001$ \\
\hline & Reversal day & 0.358 & 0.5545 \\
\hline \multirow[t]{11}{*}{ Interactions } & Training day 1 & 2.221 & 0.1474 \\
\hline & Training day 2 & 0.48 & 0.494 \\
\hline & Training day 3 & 0.686 & 0.4146 \\
\hline & Dosing day 1 & 0.554 & 0.4629 \\
\hline & Dosing day 2 & 5.39 & 0.0277 \\
\hline & Dosing day 3 & 0.011 & 0.9188 \\
\hline & Dosing day 4 & 0.269 & 0.6081 \\
\hline & Dosing day 5 & 0.052 & 0.537 \\
\hline & Test day & 0.152 & 0.6999 \\
\hline & Reversal day & 0.401 & 0.5319 \\
\hline & Timepoint & $\mathrm{t}$ value & $\mathrm{p}$ value \\
\hline \multirow[t]{11}{*}{ THC $(10 \mathrm{mg} / \mathrm{kg})$} & Training day 1 & 0.638 & 0.5337 \\
\hline & Training day 2 & 0.831 & 0.199 \\
\hline & Training day 3 & 0.652 & 0.5252 \\
\hline & Dosing day 1 & 2.693 & 0.0184 \\
\hline & Dosing day 2 & 2.408 & 0.0304 \\
\hline & Dosing day 3 & 2.855 & 0.0127 \\
\hline & Dosing day 4 & 2.825 & 0.0135 \\
\hline & Dosing day 5 & 1.386 & 0.1891 \\
\hline & $12 \mathrm{~h}$ abstinence & 0.485 & 0.652 \\
\hline & 36h abstinence & 0.903 & 0.3817 \\
\hline & Timepoint & $\mathrm{t}$ value & $\mathrm{p}$ value \\
\hline$T H C(50 \mathrm{mg} / \mathrm{kg})$ & Training day 1 & -0.168 & 0.8693 \\
\hline
\end{tabular}




$\begin{array}{ccc}\text { Training day 2 } & -0.547 & 0.5929 \\ \text { Training day 3 } & -1.378 & 0.1915 \\ \text { Dosing day 1 } & \mathbf{5 . 9 0 5} & \mathbf{< . 0 0 0 1} \\ \text { Dosing day 2 } & -3.196 & 0.0065 \\ \text { Dosing day 3 } & \mathbf{- 4 . 1 3 4} & \mathbf{0 . 0 0 1} \\ \text { Dosing day 4 } & \mathbf{- 3 . 6 7} & \mathbf{0 . 0 0 2 5} \\ \text { Dosing day 5 } & \mathbf{- 5 . 3 5 5} & \mathbf{0 . 0 0 0 1} \\ \text { 12 h abstinence } & 0.115 & 0.9099 \\ \text { 36h abstinence } & -0.159 & 0.8758\end{array}$

3.3 Experiment 3a: Acute ZCZ011 does not have anxiolytic or anxiogenic effects

ZCZ011 Marble burying dose response compared via Dunnett against vehicle

ZCZ011 Light/Dark Box dose response compared via Dunnett against vehicle

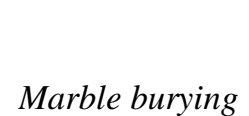

Immobility

\begin{tabular}{ccr} 
Dose $(\mathrm{mg} / \mathrm{kg})$ & $\begin{array}{l}\text { Mean } \\
\text { Difference }\end{array}$ & $\begin{array}{l}\text { Critical } \\
\text { Difference }\end{array}$ \\
\hline 2.5 & 4.57 & 4.808 \\
5 & 3.07 & 5.276 \\
10 & 1.373 & 4.593 \\
20 & -3.192 & 4.593 \\
40 & $\mathbf{- 1 0 . 5 1 3}$ & $\mathbf{4 . 8 0 8}$ \\
2.5 & -0.636 & 5.618 \\
5 & 0.849 & 5.815 \\
10 & 0.589 & 5.308 \\
20 & 4.921 & 5.308 \\
40 & $\mathbf{2 1 . 0 0 9}$ & $\mathbf{5 . 3 0 8}$ \\
& & \\
Dose $(\mathrm{mg} / \mathrm{kg})$ & Mean & Critical \\
10 & Difference & Difference \\
20 & 9.3 & 39.072 \\
40 & 21.342 & 39.072 \\
10 & 45.025 & 39.072 \\
20 & 3.05 & 37.252 \\
40 & 25.675 & 37.252 \\
& 71.925 & 37.252
\end{tabular}


ZCZ011 Open field dose response - compared via Dunnett against vehicle

Number of rears

ZCZ011 enantiomer marble burying immobility compared via Dunnett against $1 \mathrm{~min}$

\begin{tabular}{ccc} 
Dose $(\mathrm{mg} / \mathrm{kg})$ & $\begin{array}{l}\text { Mean } \\
\text { Difference }\end{array}$ & \multicolumn{1}{l}{$\begin{array}{l}\text { Critical } \\
\text { Difference }\end{array}$} \\
\hline 10 & 1.417 & 12.784 \\
20 & -3.5 & 12.784 \\
40 & $\mathbf{- 1 3 . 9 1 7}$ & $\mathbf{1 2 . 7 8 4}$
\end{tabular}

\begin{tabular}{|c|c|c|c|c|}
\hline \multirow[b]{2}{*}{ Minute (out of 20) } & \multicolumn{2}{|c|}{ ZCZ011 A } & \multicolumn{2}{|c|}{ ZCZ011 B } \\
\hline & $\begin{array}{l}\text { Mean } \\
\text { Difference }\end{array}$ & $\begin{array}{l}\text { Critical } \\
\text { Difference }\end{array}$ & $\begin{array}{l}\text { Mean } \\
\text { Difference }\end{array}$ & $\begin{array}{l}\text { Critical } \\
\text { Difference }\end{array}$ \\
\hline 2 & 2.15 & 16.016 & 2.925 & 9.115 \\
\hline 3 & 0.7 & 16.016 & 0.825 & 9.115 \\
\hline 4 & 3.763 & 16.016 & 4.7 & 9.115 \\
\hline 5 & 4.15 & 16.016 & 2.175 & 9.115 \\
\hline 6 & 7.35 & 16.016 & 4.725 & 9.115 \\
\hline 7 & 8.138 & 16.016 & 1.688 & 9.115 \\
\hline 8 & 11.213 & 16.016 & 4.2 & 9.115 \\
\hline 9 & 10.975 & 16.016 & 3.65 & 9.115 \\
\hline 10 & 14.363 & 16.016 & 4.388 & 9.115 \\
\hline 11 & 13.488 & 16.016 & 4.725 & 9.115 \\
\hline 12 & 18.988 & 16.016 & 6.188 & 9.115 \\
\hline 13 & 11.387 & 16.016 & 4.95 & 9.115 \\
\hline 14 & 27.775 & 16.016 & 8.262 & 9.115 \\
\hline 15 & 32.25 & 16.016 & 4.675 & 9.115 \\
\hline 16 & 30.45 & 16.016 & 3.15 & 9.115 \\
\hline 17 & 22.438 & 16.016 & 4.463 & 9.115 \\
\hline 18 & 33.2 & 16.016 & 9.5 & 9.115 \\
\hline 19 & 35.425 & 16.016 & 11.35 & 9.115 \\
\hline 20 & 44.575 & 16.016 & 14.488 & 9.115 \\
\hline
\end{tabular}

3.4 Experiment 3b: Somatic signs of THC withdrawal attenuated by $\underline{\text { ZCZ011 }}$

THC precipitated withdrawal with ZCZ011 attenuation in marble burying - compared via
Marble burying

\begin{tabular}{ccc} 
Comparison & t value & p value \\
\hline Vehicle v. THC & $\mathbf{3 . 4 6 6}$ & $\mathbf{0 . 0 0 3 8}$ \\
Vehicle v. THC+ZCZ 10 & $\mathbf{6 . 3 1 1}$ & $<.0001$
\end{tabular}


planned $\mathrm{t}$ tests with Bonferroni correction (significant if $\mathrm{p} \leq 0.0125$ ); df: 14

THC precipitated withdrawal with ZCZ011 attenuation in somatic signs - compared via Bonferroni (significant if $\mathrm{p}<0.005$ )

THC precipitated withdrawal with ZCZ011 enantiomer $(5 \mathrm{mg} / \mathrm{kg}$ only) attenuation in somatic signs - compared via Bonferroni (significant if $\mathrm{p} \leq 0.005)$
Paw tremors

Paw tremors
Vehicle v. THC+ZCZ 40

0.858

0.4051

\begin{tabular}{c} 
Comparison \\
\hline Vehicle v. THC \\
Vehicle v. THC+ZCZ 1 \\
Vehicle v. THC+ZCZ 3.33 \\
Vehicle v. THC+ZCZ 10 \\
THC v. THC+ZCZ 1 \\
THC v. THC+ZCZ 3.33 \\
THC v. THC+ZCZ 10 \\
THC+ZCZ 1 v. THC+ZCZ \\
3.33
\end{tabular}

THC+ZCZ 1 v. THC+ZCZ 10

THC+ZCZ 3.33 v. THC+ZCZ

10

Vehicle v. THC

Vehicle v. THC + ZCZ 1

Vehicle v. THC+ZCZ 3.33

Vehicle v. THC + ZCZ 10

THC v. THC + ZCZ 1

THC v. THC+ZCZ 3.33

THC v. THC+ZCZ 10

THC+ZCZ 1 v. THC+ZCZ 3.33

THC+ZCZ 1 v. THC+ZCZ 10

THC+ZCZ 3.33 v. THC+ZCZ

10

Mean critical

difference difference

$\begin{array}{lll}\mathbf{- 4 6 . 8 5 7} & 32.277 & \mathbf{0 . 0 0 0 1}\end{array}$

$\begin{array}{lll}\mathbf{- 3 6 . 6 9 6} & 31.252 & \mathbf{0 . 0 0 1 2}\end{array}$

$\begin{array}{lll}37.286 & 32.277 & \mathbf{0 . 0 1 5}\end{array}$

$\begin{array}{lll}-12.696 & 31.252 & 0.2296\end{array}$

$\begin{array}{lll}10.161 & 31.252 & 0.3343\end{array}$

$\begin{array}{lll}9.571 & 32.277 & 0.378\end{array}$

$\begin{array}{lll}34.161 & 31.252 & \mathbf{0 . 0 0 2 4}\end{array}$

$\begin{array}{lll}-0.589 & 31.252 & 0.975\end{array}$

$\begin{array}{lll}24 & 30.192 & 0.0226\end{array}$

$\begin{array}{lll}24.589 & 31.252 & 0.0239\end{array}$

$\begin{array}{lll}\mathbf{- 7 . 2 8 6} & 5.652 & \mathbf{0 . 0 0 0 5}\end{array}$

$\begin{array}{lll}\mathbf{- 5 . 6 2 5} & 5.473 & \mathbf{0 . 0 0 4}\end{array}$

$\begin{array}{lll}-3.286 & 5.652 & 0.0892\end{array}$

$\begin{array}{lll}-2.875 & 5.473 & 0.123\end{array}$

$\begin{array}{lll}1.661 & 5.473 & 0.3671\end{array}$

$4 \quad 5.652 \quad 0.0406$

$\begin{array}{lll}4.411 & 5.473 & 0.0209\end{array}$

$\begin{array}{lll}2.339 & 5.473 & 0.2067\end{array}$

$\begin{array}{lll}2.75 & 5.287 & 0.1267\end{array}$

$\begin{array}{lll}0.411 & 5.473 & 0.8824\end{array}$

Mean critical difference difference

$\begin{array}{lll}\mathbf{- 3 8 . 6 2 5} & 16.135 & <.0001\end{array}$

$\begin{array}{lll}-1.875 & 16.135 & 0.7298\end{array}$

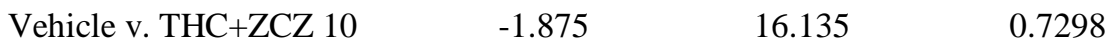

$\begin{array}{llll}\text { Vehicle v. THC+ZCZ A } & -10.375 & 16.135 & 0.0622\end{array}$

$\begin{array}{llll}\text { Vehicle v. THC+ZCZ B } & -8.375 & 16.135 & 0.1289\end{array}$ 


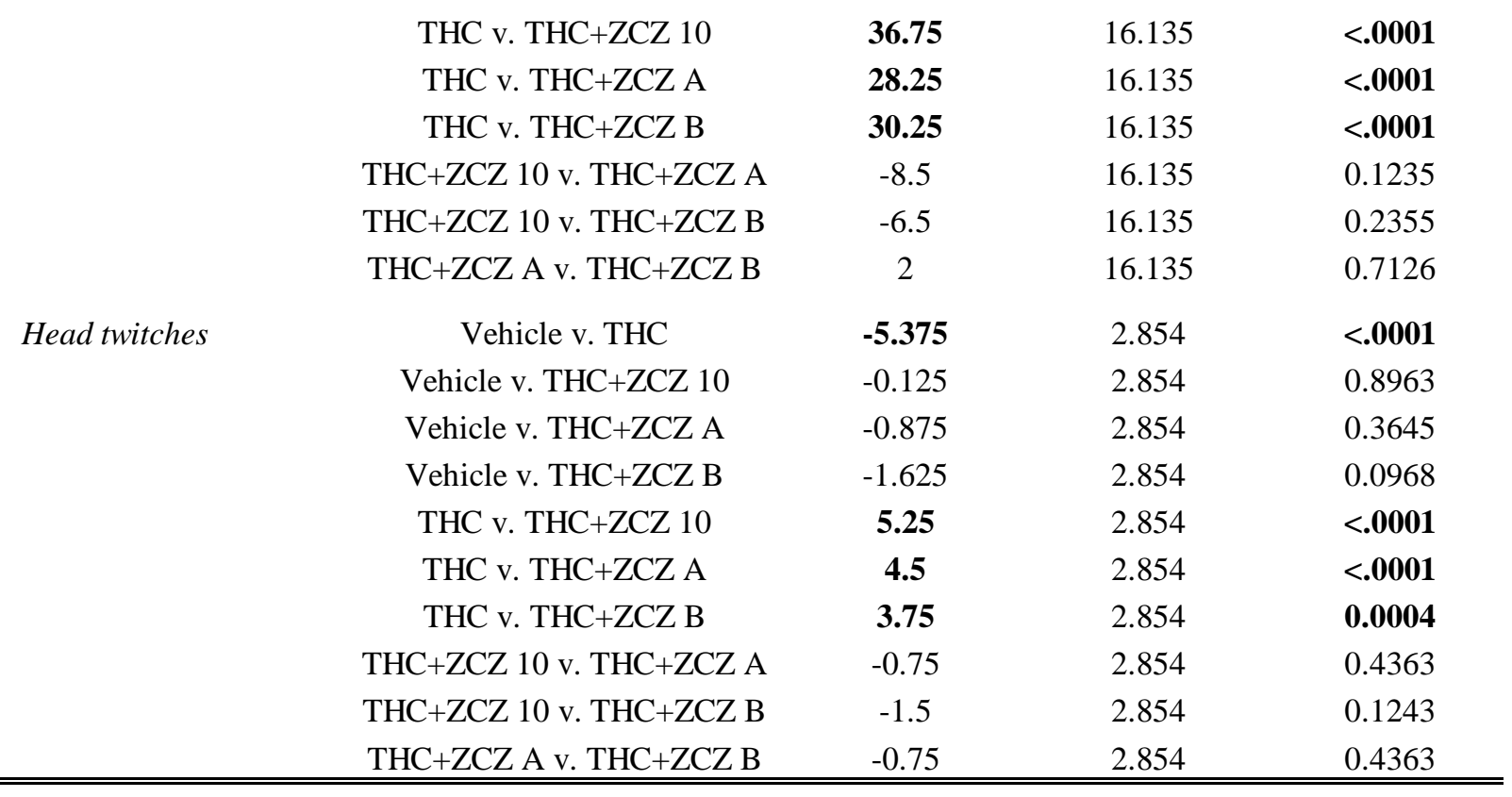

